\title{
Article
}

\section{Direct Interaction of Mitochondrial Cytochrome $c$ Oxidase with Thyroid Hormones: Evidence for Two Binding Sites}

\author{
Ilya P. Oleynikov ${ }^{1}$, Natalia V. Azarkina ${ }^{1 *}$ and Tatiana V. Vygodina ${ }^{1}$ \\ 1 A.N. Belozersky Institute of Physico-Chemical Biology, M.V. Lomonosov Moscow State University, Leninskie \\ gory 1, Bld. 40, 119992 Moscow, Russia \\ * Correspondence: azarkina@yahoo.com
}

Received: date; Accepted: date; Published: date

\begin{abstract}
Thyroid hormones regulate tissue metabolism establishing an energy balance in the cell, in particular by affecting oxidative phosphorylation. Their long-term impact is mainly associated with changes in gene expression, while the short-term effects may differ in mechanism. Our work is devoted to short-term effects of hormones T2, T3, and T4 on mitochondrial cytochrome $c$ oxidase $(\mathrm{CcO})$ mediated by a direct contact with the enzyme. The data obtained indicate the existence of two separate sites of $\mathrm{CcO}$ interaction with thyroid hormones differing in location, affinity and specificity to hormone binding. It is shown that $\mathrm{T} 3$ and $\mathrm{T} 4$ but not $\mathrm{T} 2$ inhibit oxidase activity of $\mathrm{CcO}$ in solution and on membrane preparations with $K_{\mathrm{i}} \approx 100-200 \mu \mathrm{M}$. In solution, T3 and T4 compete in a 1:1 ratio with the detergent dodecyl-maltoside for binding to the enzyme. Peroxidase and catalase partial activities of $\mathrm{CcO}$ are not sensitive to hormones while electron transfer from heme $a$ to the oxidized binuclear center is affected. We believe that T3 and T4 are ligands of the Bile Acid Binding Site found in the 3D structure of $\mathrm{CcO}$ by Ferguson-Miller's group, and hormone induced inhibition is associated with dysfunction of the K- proton channel. Similar conclusion we made recently with regard to steroid-like compounds. It is found that T2, T3, and T4 inhibit superoxide generation by oxidized $\mathrm{CcO}$ in the presence of excess $\mathrm{H}_{2} \mathrm{O}_{2}$. Inhibition is characterized by $K_{\mathrm{i}}$ values of $0.3-5 \mu \mathrm{M}$ and apparently affects the formation of $\mathrm{O}_{2}{ }^{--}$at the protein surface. The second binding site for thyroid hormones presumably coincides with the point of tight $\mathrm{T} 2$ binding on the Va subunit described in the literature.
\end{abstract}

Keywords: cytochrome oxidase; thyroid hormones; steroid hormones; Bile Acids Binding Site; regulation

\section{Introduction}

Cytochrome $c$ oxidase $(\mathrm{CcO})$ (for the recent reviews see $[1,2]$ ) is the terminal enzyme of the respiratory chain located in the coupling membranes of mitochondria and aerobic bacteria. CcO catalyzes the reduction of oxygen to water providing the cell with the energy released. Electrons arriving from cytochrome $c$ are transferred along the redox centers: $\mathrm{CuA} \rightarrow$ low-spin heme $a \rightarrow a_{3} / \mathrm{Cu}_{\mathrm{B}} \rightarrow \mathrm{O}_{2}$. Catalytic center of the enzyme is a binuclear center $a_{3} / \mathrm{Cu}$ formed by closely spaced high-spin heme $a_{3}$ and copper ion. Four-electron reduction of oxygen to water in $a_{3} / \mathrm{Cu}$ center is coupled to proton translocation and energy transduction to $\Delta \mu \mathrm{H}^{+}$. Mitochondrial $\mathrm{CcO}$ consists of 13 subunits [3] three largest of which (catalytic subunit I containing heme $a$ and $a_{3} / \mathrm{Cu}$ centers, subunit II carrying cytochrome $c$ binding site and $\mathrm{CuA}_{\mathrm{A}}$ and subunit III) are homologous to the subunits of bacterial enzymes and encoded by mitochondrial DNA. The role of the rest smaller subunits encoded by the nuclear genome is not clear completely and presumed to be related to enzyme regulation [4].

The catalytic cycle of $\mathrm{CcO}$ is subdivided into two phases: eu-oxidase and peroxidase [5, 6]. In the eu-oxidase phase, the oxidized binuclear center $a_{3}{ }^{3+} / \mathrm{Cu}^{2+}$ is reduced to $a_{3}{ }^{2+} / \mathrm{Cu}^{+}$by two electrons and binds $\mathrm{O}_{2}$. One of the oxygen atoms is reduced and leaves the active center as $\mathrm{H}_{2} \mathrm{O}$, whereas the other remains bound to heme $a_{3}$ as an oxene ligand $\left(a_{3}{ }^{4+}=\mathrm{O}^{2-}\right)$ which is accompanied by generation of an electron vacancy on the nearby tyrosine residue. The next peroxidase phase is very similar to the reaction catalyzed by 
peroxidases: oxoferryl intermediate I $\left(a 3^{4+}=\mathrm{O}^{2-}-\mathrm{Tyr}^{\bullet}\right)$ converts into intermediate II $\left(a 3^{4+}=\mathrm{O}^{2-} \mathrm{Tyr}\right)$ with subsequent transition to the oxidized state of the binuclear center $\left(a_{3}{ }^{3+} / \mathrm{CuB}^{2+}\right)$ and release of the second $\mathrm{H}_{2} \mathrm{O}$ molecule. During the catalytic cycle, all protons (4 "chemical" protons consumed to form $\mathrm{H}_{2} \mathrm{O}$, and 4 "vector" protons pumped from mitochondrial matrix to intermembrane space) are transferred inside the protein via $\mathrm{K}$ - and $\mathrm{D}$ - proton channels named after their critical amino acid residues. It is accepted that in eu-oxidase phase two "chemical" protons are delivered to the binuclear center via K-channel. In peroxidase phase K-channel is closed and the rest 6 protons ("chemical" and "vector") are transferred across the membrane through channel D (for details see reviews [6 - 8]).

New budding perspectives for studies of $\mathrm{CcO}$ regulation have arisen from the series of works from Ferguson-Miller's laboratory. The authors revealed a conserved hydrophobic cavity in the crystal structure of $\mathrm{CcO}$ from Rhodobacter sphaeroides and bovine heart mitochondria and suggested that it can represent a binding site for small amphipathic molecules [9-13]. The cavity is located on the inner side of the membrane at the boundary of the subunits I and II and near the mouth of the proton channel K. On the X-ray structures of $\mathrm{CcO}$ from mitochondria and $R$. sphaeroides it was occupied by the bile acid molecule (cholate or deoxycholate, respectively) used in crystallization so the cavity was called the Bile Acid Binding Site (BABS). In the structure of bacterial enzyme, was also visualized a decyl-maltoside detergent molecule located in the immediate vicinity of BABS and thought to reach it in some conformations $[9,11]$. In the structure of eukaryotic $\mathrm{CcO}$ a similar place is occupied by a tightly bound phospholipid molecule [9]. The computational analysis of the BABS structure reveals its possible affinity to a number of physiologically active molecules including steroids, triiodine-thyronine, nicotinamine, flavin, some nucleotides and products of heme decomposition [11, 12]. In some cases and in particular for triiodine-thyronine the inhibition of $\mathrm{CcO}$ from $R$. sphaeroides was shown experimentally [12]. At the same time, no effect of steroid sex hormones on the activity of bacterial enzyme was found. However our group has shown recently that steroid hormones as well as structurally similar to them secosteroids and detergent Triton X-100 (which spatially mimic estrogen molecules in some respects) are able to bind with BABS and inhibit the activity of mitochondrial $\mathrm{CCO}[14,15]$.

It seems that BABS has a fairly broad specificity and is able to interact with a variety of physiologically active molecules of amphipathic structure. Of especial interest is an inhibitory effect of the thyroid hormone $\mathrm{T} 3$ on the activity of wild-type $\mathrm{CcO}$ from R. sphaeroides ( $\mathrm{K}_{\mathrm{i}}$ in the range of 30-210 $\mu \mathrm{M}$, depending on the conditions of assay) [12]. Obviously, triiodine-thyronine cannot be considered as a physiological regulator of bacterial enzyme but in case of eukaryotic analog its regulatory function looks quite probable.

Thyroid and steroid hormones are metabolic regulators of the highest rank and their signaling pathways intersect in many cases [16 - 19]. The ability of such regulatory molecules to influence the activity of $\mathrm{CcO}$, a key enzyme of aerobic metabolism, through direct interaction seems quite unexpected. Investigation of this phenomenon can be important from different points of view: in physiological aspect, for better understanding of $\mathrm{CcO}$ catalytic mechanism, and, finally, in terms of the evolution of regulatory systems. The aim of present work is to study the effects of the "classic" thyroid hormones T3 (L-3,5,3'triiodine-thyronine) and T4 (thyroxine, or L-3,5,3',5'tetraiodo-thyronine), as well as T2 (3,5-diiodothyronine), the most active product of $\mathrm{T} 3$ deiodination, on the activities of mitochondrial $\mathrm{CcO}$ in solution and in membrane preparations. The results obtained suggest that mitochondrial enzyme contains two different sites of interaction with thyroid hormones.

\section{Materials and Methods}

Chemicals. Thyroxine (T4), 3,5,3' triiodotyronine (T3), 3,5 diodotyronine (T2), sodium dithionite, cholate, succinate, ATP, cytochrome $c$ (type III from equine heart), TMPD (N,N, $\mathrm{N}^{\prime}, \mathrm{N}^{\prime}$-tetramethyl- $p$ phenylenediamine), hexaammineruthenium(III), L-ascorbic acid, potassium ferro- and ferricyanide, asolectin from soya beans (type II S), superoxide dismutase from bovine erythrocytes, xanthine oxidase from bovine milk, hypoxanthine and hydrogen peroxide were from Sigma-Aldrich (USA). pH-buffers, $\mathrm{MgSO}_{4}$, sucrose and EDTA (ethylenediaminetetraacetic acid) were from Amresco (USA). Water soluble tetrazolium (WST-1) was from Dojindo Molecular Technologies (Japan). Bio-Beads SM-2 Adsorbent 20-50 mesh was from Bio-Rad (USA). Dodecyl-maltoside of "Sol-Grade" type was from Anatrace (USA).

Thyroid hormones T4, T3 and T2 were dissolved in $0.1 \mathrm{M} \mathrm{NaOH}$. 
Hydrogen peroxide solution (about $30 \%$ ) was kept at $4{ }^{\circ} \mathrm{C}$, before the experiments the concentration was checked spectrophotometrically using molar extinction coefficient $2240=40 \mathrm{M}^{-1} \mathrm{~cm}^{-1}$ [20]. Marketable adsorbent balls Bio-Beads were activated by washing 3 times with methanol $(10 \mathrm{~g}$ of balls were stirred for $20 \mathrm{~min}$ with $60 \mathrm{ml}$ methanol) followed by slow rinse with water (c.a. $700 \mathrm{ml})$ on a funnel. Activated balls were kept covered by water in refrigerator.

Preparations.

Cytochrome coxidase $(\mathrm{CcO})$ was purified from heart mitochondria of Bos taurus. Hearts were purchased from abattoir of Pushkinsky Myasnoy Dvor Ltd. (Pushkino, Moscow region) and stored on ice for 2-3 hrs after slaughter until isolation procedure began. $\mathrm{CCO}$ was isolated according to a modified method of Fowler at al. [21] described previously [22]. The concentration was determined from the difference absorption spectra (dithionite reduced vs air oxidized) using molar extinction coefficient $\Delta \varepsilon 605-$ $630 \mathrm{~nm}=27 \mathrm{mM}^{-1} \mathrm{~cm}^{-1}$. CcO destined for reconstitution into proteoliposomes was preliminarily purified on a sucrose gradient as described in [23].

$\mathrm{CcO}$ reconstruction into phospholipid vesicles. Asolectin was dispersed to concentration of $60 \mathrm{mg} / \mathrm{ml}$ in $50 \mathrm{mM}$ potassium phosphate buffer ( $\mathrm{pH}$ 7.6) supplemented with $2 \mathrm{mM} \mathrm{MgSO}_{4}$ and $1.3 \%$ cholate. The mixture was bubbled with argon and then sonicated 5 times for $30 \mathrm{~s}$ in an ultrasonic desintegrator (Branson Sonifier 150, USA). The residual nonsonicated material and metal concomitants from pestle were removed by centrifugation for $5 \mathrm{~min}$ at $14000 \mathrm{rpm}$ in a mini-centrifuge (Eppendorf, Germany). $\mathrm{CcO}$ was added to a clarified lipid solution up to $1 \mu \mathrm{M}$ and stirred for $30 \mathrm{~min}$. Liposomes with $\mathrm{CcO}$ were formed during the process of detergent removing achieved by vigorous stirring the sample with BioBeads balls. The balls were added at room temperature, sequentially: $80 \mathrm{mg} / \mathrm{ml}$ of suspension ( $30 \mathrm{~min}$ stirring), more $80 \mathrm{mg}$ (60 min stirring), more $160 \mathrm{mg}$ (120 min stirring), more $160 \mathrm{mg}$ (120 min stirring). Proteoliposomes were collected and dialysed overnight against $50 \mathrm{mM}$ potassium phosphate buffer $\mathrm{pH}$ 7.6 supplied with $2 \mathrm{mM} \mathrm{MgSO}_{4}$, at $+4^{\circ} \mathrm{C}$. The orientation of $\mathrm{CcO}$ in the membrane vesicles was assessed by comparing heme $a$ reduction levels achieved in the presence of $5 \mathrm{mM}$ ascorbate $+2.5 \mu \mathrm{M}$ cytochrome $c$ alone, or with $0.1 \mathrm{mM}$ TMPD as a membrane-penetrating redox mediator.

Isolation of rat liver mitochondria. Rat liver mitochondria were isolated by differential centrifugation as described in [24] in a medium containing $250 \mathrm{mM}$ sucrose, $5 \mathrm{mM}$ MOPS, $1 \mathrm{mM}$ EGTA, and bovine serum albumin $(0.5 \mathrm{mg} / \mathrm{ml}), \mathrm{pH}$ 7.4. The final washing was performed in a medium of the same composition. Protein concentration was determined by Biuret method. Handling of animals and experimental procedures with them were conducted in accordance with the international guidelines for animal care and use and were approved by the Institutional Ethics Committee of Belozersky Institute of Physico-Chemical Biology at Moscow State University. The incubation medium contained $250 \mathrm{mM}$ sucrose, $5 \mathrm{mM}$ MOPS, and $1 \mathrm{mM}$ EGTA, $\mathrm{pH}$ 7.4. The mitochondrial protein concentration in the assay was $0.8 \mathrm{mg} / \mathrm{ml}$. Mitochondria were kept freezed at $-20^{\circ} \mathrm{C}$ and thawed just before experiment. A single freeze-thaw procedure resulted in destruction of the outer mitochondrial membrane.

Preparation of submitochondrial particles (SMP). The heavy fraction of bovine heart mitochondria was suspended in $40 \mathrm{ml}$ of $0.3 \mathrm{M}$ sucrose supplemented with $5 \mathrm{MM} \mathrm{MgSO}_{4}, 1 \mathrm{MM}$ succinate, $1 \mathrm{mM}$ ATP, and $10 \mathrm{mM}$ Hepes $\mathrm{pH}$ 8.0. The mixture was bubbled with argon and then sonicated 2 times each for $55 \mathrm{~s}$ in an ultrasonic disintegrator USDG-2T (USSR), at $44 \mathrm{kHz}, 0.4 \mathrm{~A}$. After sonication, $\mathrm{pH}$ of the mixture was adjusted to 8.0 by Tris powder. Mitochondrial debris was removed by centrifugation for $12 \mathrm{~min}$ at 15000 rpm (Beckman JA-20, USA). SMP were precipitated from supernatant at $100000 \mathrm{~g}$ for $1 \mathrm{~h}$, washed by 0.3 $\mathrm{M}$ sucrose with $10 \mathrm{MM}$ Hepes $\mathrm{pH} 7.5$ and precipitated as previously. Final precipitate was suspended in a small volume of the same buffer and freezed [25]. In order to determine $\mathrm{CcO}$ concentration in the sample, small amount of SMP was solubilized in $50 \mathrm{mM}$ Hepes/Tris buffer, $\mathrm{pH} 7.6$ containing 1\% DM.

Spectroscopic assays were carried out in a standard semi-micro cuvette (Hellma, Germany) with blackened side walls and $10 \mathrm{~mm}$ light pathway.

Absolute absorption spectra were recorded with $3 \mathrm{~nm}$ slit width, at speed of $2 \mathrm{~nm} / \mathrm{s}$, on a doublebeam spectrophotometer Cary 300 Bio (Varian, USA).

The kinetics of spectral changes was monitored on spectrophotometer SLM Aminco DW-2000 (SLM Instruments, USA) in a dual-wavelength mode. 
The stopped-flow experiments were performed using a stopped-flow spectrophotometer (Applied Photophysics SX-20, UK) operated in a diode array mode, using a $20 \mu \mathrm{l}$ cell with $1 \mathrm{~cm}$ optical pathway. The spectra in the $280-720 \mathrm{~nm}$ range were collected with a minimal interval of $1 \mathrm{~ms}$.

Mesurements of enzymetic activities.

$\mathrm{CcO}$ activity was monitored using two different methods.

The rate of oxygen consumption was measured with a covered Clark-type electrode using an Oxygraph-type device ("Oxytherm" from Hansatech, UK), in a thermostatted cell at $25^{\circ} \mathrm{C}$ with permanent stirring. $5 \mathrm{mM}$ ascorbate, $0.1 \mathrm{mM}$ TMPD and $10 \mu \mathrm{M}$ cytochrome $c$ were used together as an oxidation substrate. The assays were performed in the Basic Medium containing $50 \mathrm{mM}$ Hepes/Tris buffer, $\mathrm{pH} 7.6,0.1 \mathrm{mM}$ EDTA, $50 \mathrm{mM} \mathrm{KCl}$ and $0.05 \%$ dodecyl-maltoside (DM) to maintain the enzyme in the solubilized state. In some experiments DM concentration varied from $0.02 \%$ to $1 \%$ as indicated in legends to the figures. Concentrations of DM are given throughout the text both in $\%$ and in $\mathrm{mM}(0.05 \% \approx$ $1.0 \mathrm{mM} \mathrm{DM})$. Turnover (TN) values of $\mathrm{CCO}$ refer to electrons transferred in 1 second per enzyme monomer.

The rate of cytochrome $c^{2+}$ oxidation was followed spectrophotometrically by absorption difference at $550 \mathrm{~nm}$ vs $535 \mathrm{~nm}$ reference in a dual-wavelength mode. The initial linear part of the traces was used for calculations. Cytochrome $c$ was reduced beforehand by dithionite. The remaining of dithionite was removed by passing the sample though Sephadex G-25 coarse column.

Peroxidase activity of $\mathrm{CcO}$ was assayed in the Basic Medium $\mathrm{pH} 7.6$ following spectrophotometrically peroxidation of ferrocyanide by absorption difference at $420 \mathrm{~nm}$ vs $500 \mathrm{~nm}$ reference. In order to obtain redox-buffer with $\mathrm{Em}_{\mathrm{m}} \approx 420 \mathrm{mV}$, equal amounts of ferri- and ferrocyanide were mixed. No ferrocyanide oxidase activity was observed until the peroxidase reaction was initiated by addition of $4 \mathrm{mM} \mathrm{H}_{2} \mathrm{O}_{2}$.

Catalase activity of $\mathrm{CcO}$ was detected by Clark-type electrode monitoring oxygen release, in the presence of excess hydrogen peroxide $(12 \mathrm{mM})$, in $30 \mathrm{mM}$ potassium-phosphate buffer $\mathrm{pH} 7.1$ supplemented with $2 \mathrm{mM}$ EDTA and $0.05 \% \mathrm{DM}$, as described in [26]. The observed oxygen release was completely sensitive to cyanide.

The reaction of superoxide generation catalyzed by $\mathrm{CcO}$ in the presence of excess hydrogen peroxide was assayed in the Basic Medium, pH 7.6 by the classic method [27], monitoring superoxide dismutase sensitive reduction of tetrazolium salts to fomazan. Water soluble tetrazolium dye (WST-1) reduction was followed as absorption difference at $440 \mathrm{~nm}$ vs $550 \mathrm{~nm}$ reference.

Oxoferryl intermediates formation was monitored using stopped-flow technics. $6.5 \mu \mathrm{M} \mathrm{CcO}$ in the Basic Medium, pH 8.1 supplemented with $0.1 \%$ DM, $0.05 \mathrm{mM}$ ferricyanide and, when necessary, $0.5 \mathrm{mM}$ $\mathrm{T} 4$ was rapidly mixed with the equal volume of the same buffer containing $2 \mathrm{mM} \mathrm{H}_{2} \mathrm{O}_{2}$.

Data processing was mainly performed using Origin 7 and 9 Microcal software (https://www.originlab.com/). For the stopped-flow data processing, Pro Kineticist software provided with the Applied Photophysics SX-20 instrument was also used.

\section{Results}

\subsection{Inhibition of cytochrome oxidase activity}

\subsubsection{Inhibition of solubilized enzyme}

The effect of thyroid hormones T2, T3, and T4 on the oxidase reaction catalyzed by solubilized $\mathrm{CcO}$ from bovine heart mitochondria has been studied. It was found that hormones $\mathrm{T} 3$ and $\mathrm{T} 4$ at submillimolar concentrations inhibit significantly $\mathrm{CcO}$ activity. The sensitivity to the inhibitor decreased with increasing concentration of $\mathrm{DM}$, a mild detergent added to the medium to keep $\mathrm{CcO}$ in a soluble form.

Figure 1 represents the main features of the inhibitory effects on $\mathrm{CcO}$ activity induced by thyroid hormones. 

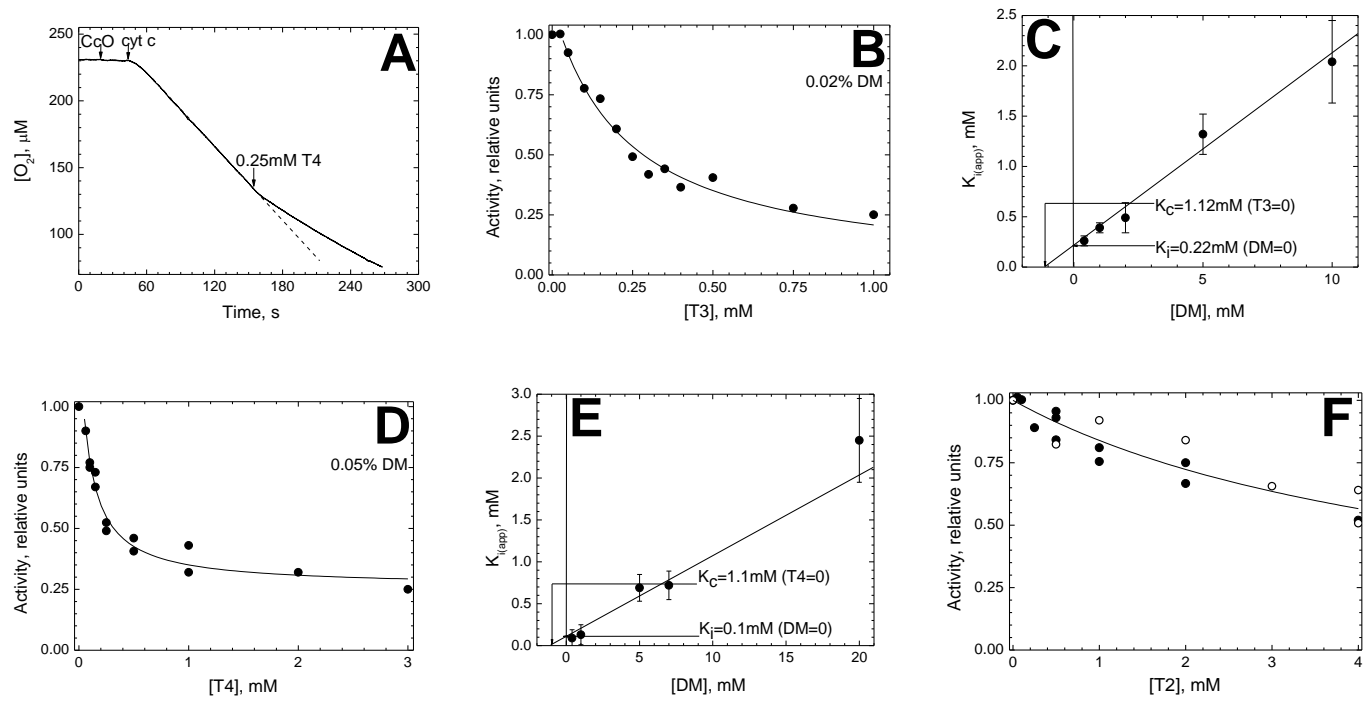

Figure 1. Inhibition of the solubilized $\mathrm{CcO}$ oxidase activity by thyroid hormones. (a) A typical experiment demonstrating inhibition of cytochrome $c$ oxidase activity by thyroid hormones. Oxygen consumption was registered in the Basic Medium, pH 7.6 supplemented with $5 \mathrm{mM}$ ascorbate and 0.1 mM TMPD. Additions of $\mathrm{CcO}(20 \mathrm{nM})$, cytochrome $c(10 \mu \mathrm{M})$ and $\mathrm{T} 4(0.25 \mathrm{mM})$ are shown by the arrows. The trace is corrected for ascorbate autooxidation. To highlight the inhibitory effect, the trace in the absence of T4 is shown by the dotted line. (b) Titration of $\mathrm{CcO}$ activity by T3 at $0.02 \%$ DM. Other conditions are mainly as in panel a. Experimental data (circles) are approximated by function (1), see the text. Activity (the ratio of the reaction rate after the onset of inhibition to the initial reaction rate) is given in relative units. (c) Dependence of an apparent $K_{\mathrm{i}}$ for $\mathrm{T} 3$ on DM concentrations. The $K_{\mathrm{i}(\mathrm{app})}$ values are determined from the approximation of the experimental data by function (1), see panel $b$. The segment being cut off on the $Y$-axis indicates the true inhibition constant $K_{\mathrm{i}}$ for $\mathrm{T} 3$ in the absence of $\mathrm{DM}$, the segment being cut off on the $\mathrm{X}$ axis in its negative area indicates the value of dissociation constant for DM in the absence of T3, $K_{c}$ (both segments are pointed out by the arrows). (d) Titration of $\mathrm{CcO}$ activity by $\mathrm{T} 4$ at $0.05 \% \mathrm{DM}$. The conditions are mainly as in panel a. Experimental data (circles) are approximated by function (1), see the text. Activity (the ratio of the reaction rate after the onset of inhibition to the initial reaction rate) is given in relative units. (e) Dependence of an apparent $K_{\mathrm{i}}$ for T4 on DM concentrations. The $K_{\mathrm{i}(a p p)}$ values are determined from the approximation of the experimental data by function (1), see panel d. The segment being cut off on the $\mathrm{Y}$ axis indicates the true inhibition constant $K_{\mathrm{i}}$ for $\mathrm{T} 4$ in the absence of DM, the segment being cut off on the $\mathrm{X}$ axis in its negative area indicates the value of dissociation constant for DM in the absence of T4, $K_{\mathrm{c}}$ (both segments are pointed out by the arrows). (f) Titration of $\mathrm{CcO}$ activity by $\mathrm{T} 2$ at $0.05 \%$ (filled signs) and $1 \%$ (open signs) DM. Other conditions are mainly as in panel a. The entire dataset is approximated by function (1), see the text. Activity (the ratio of the reaction rate after the onset of inhibition to the initial reaction rate) is given in relative units.

A typical recording illustrating deceleration of the rate of oxygen consumption by $\mathrm{CcO}$ after addition of T4 is shown in Figure 1a. The reaction is carried out in the Basic Medium in the presence of cytochrome $c$ (a direct electron donor), ascorbate (as reductant), and TMPD (as redox mediator). It proceeded at a constant rate corresponding to the enzyme turnover about $200 \mathrm{e} / \mathrm{s}$. Addition of $0.25 \mathrm{mM}$ $\mathrm{T} 4$ to the turning over enzyme decreased approximately two times the rate of oxygen consumption. The constant rate is reached $\sim 20 \mathrm{~s}$ after the addition which slightly exceeds the mixing time in this experiment (5-10 s). A similar effect on the oxidase activity of solubilized $\mathrm{CcO}$ is induced by T3 (data not shown).

The dependence of the normalized $\mathrm{CcO}$ activity on $\mathrm{T} 3$ concentration obtained in the presence of $0.02 \%(0.4 \mathrm{mM}) \mathrm{DM}$ is shown in Figure $1 \mathrm{~b}$. As seen, the experimental data are well described by the theoretical function

$$
v=\frac{1}{1+\frac{I}{K_{i(a p p)}}}
$$

where $v$ is the normalized rate of the oxidase reaction, $I$ is the concentration of the hormone, and $K_{\mathrm{i}(\mathrm{app})}$ is the apparent inhibition constant at a given concentration of DM. It was found that similar to steroid hormones [14], the inhibition by thyroid hormones depends significantly on DM concentration in the medium. The dependence of $K_{\mathrm{i}(\mathrm{app})}$ values on [DM] is shown in Figure 1c. In the range tested (0.4 - $10 \mathrm{mM}$ 
$\mathrm{DM})$, the dependence is close to linear which points out an 1:1 competition between T3 and DM for binding with the enzyme. The segments cut off by a linear function on the $\mathrm{Y}$ - and $\mathrm{X}$-axis (in its negative part) allow to determine the true inhibition constant for $\mathrm{T} 3, K_{\mathrm{i}} \approx 0.22 \mathrm{mM}$ (at [DM] $=0$ ) as well as the dissociation constant of the DM-CcO complex, $K_{\mathrm{c}} \approx 1.12 \mathrm{mM}$ (at zero concentration of the inhibitor). It should be noted that at high DM concentrations titration curves are slightly shifted along the $\mathrm{X}$-axis to the right, without changing the values of $K_{\mathrm{i}(a p p)}$. A similar effect was observed earlier on steroids [14] and Triton TX-100 [15]. Though the exact origin of this "lag-phase" remains unclear we assume it to be associated with interaction of the inhibitor and the empty DM micelles.

Figure $1 \mathrm{~d}$ demonstrates the dependence of normalized $\mathrm{CcO}$ activity on concentration of $\mathrm{T} 4$ at $[D M]=0.05 \%(1 \mathrm{mM})$. As previously, the data is well approximated by hyperbolic function that allows to

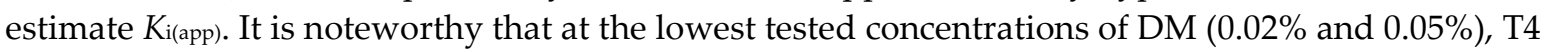
inhibits only $70-80 \%$ of enzyme activity, while $\mathrm{T} 3$ induces complete inhibition of $\mathrm{CcO}$ activity at all tested DM concentrations including $0.02 \%$ ( $c f$. to Figure $1 \mathrm{~b}$ ). Such an effect of DM concentration on the level of inhibition was observed earlier with testosterone [14]. Figure 1e represents the dependence of $K_{\mathrm{i}(a p p)}$ values for T4 on [DM]. As with T3 (cf. Figure 1c), it is close to linear and enables to estimate the values of the constants: $K_{\mathrm{i}} \approx 0.1 \mathrm{mM}$ T4 and $K_{\mathrm{c}} \approx 1.1 \mathrm{mM} \mathrm{DM}$.

Figure $1 \mathrm{f}$ illustrates the effect of $\mathrm{T} 2$. In contrast to $\mathrm{T} 3$ and $\mathrm{T} 4$ it does not actually inhibit the oxidase reaction. A slight suppression of activity is observed only in the millimolar concentration range. The $K_{\mathrm{i}}$ value for $\mathrm{T} 2$ obtained after approximation of the experimental data with the theoretical function (1) is $5.2 \pm 0.5 \mathrm{mM}$. It is symptomatic that unlike T3 and T4 hormones, the inhibitory effect of T2 is not sensitive to DM concentrations in the medium (compare filled and empty symbols corresponding to data obtained at $0.05 \%$ and $1 \% \mathrm{DM}$ ). The same results were obtained when DM was replaced by $1 \%$ Tween 20 (data not shown). Moreover, it was found that $K_{\mathrm{i}(a p p)}$ for $\mathrm{T} 2$ decreased five times when $\mathrm{CcO}$ activity was assayed by ferrocytochrome $c$ oxidation, an alternative method that requires a 40-50 times lower enzyme concentration as compared to oxygen consumption measurements. A series of control experiments confirmed that changes in the $K_{\text {i(app) }}$ value were associated precisely with variation of the enzyme concentration rather than other distinctive features of the alternative method (the absence of ascorbate and TMPD or the presence of a small admixture of oxidized cytochrome $c$ ). The dependence of the effect on the enzyme concentration indicates probable non-specificity of $\mathrm{CcO}$ interaction with $\mathrm{T} 2$. It is important to note that similar change in $\mathrm{CcO}$ concentration does not induce any changes in inhibition parameters of hormones $\mathrm{T} 3$ and $\mathrm{T} 4$.

\subsubsection{Inhibition of $\mathrm{CcO}$ in the membrane}

Our data confirm that thyroid hormones inhibit mitochondrial $\mathrm{CcO}$ not only in solution but also in membranes.

At first, the effect of thyroid hormones on $\mathrm{CcO}$ incorporated into azolectin vesicles has been studied. It was found (see Section 2) that $70 \%$ of the enzyme molecules were embedded in the "right-sideout" orientation. $\mathrm{CcO}$ activity in proteoliposomes was assayed in the same way as in solution except the absence of detergent and presence of protonophore in the medium (see legends to the Figures).
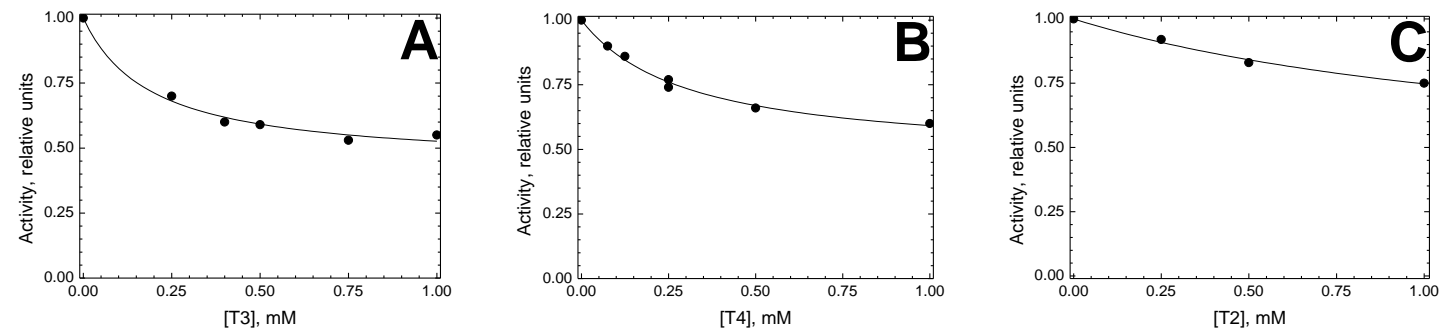

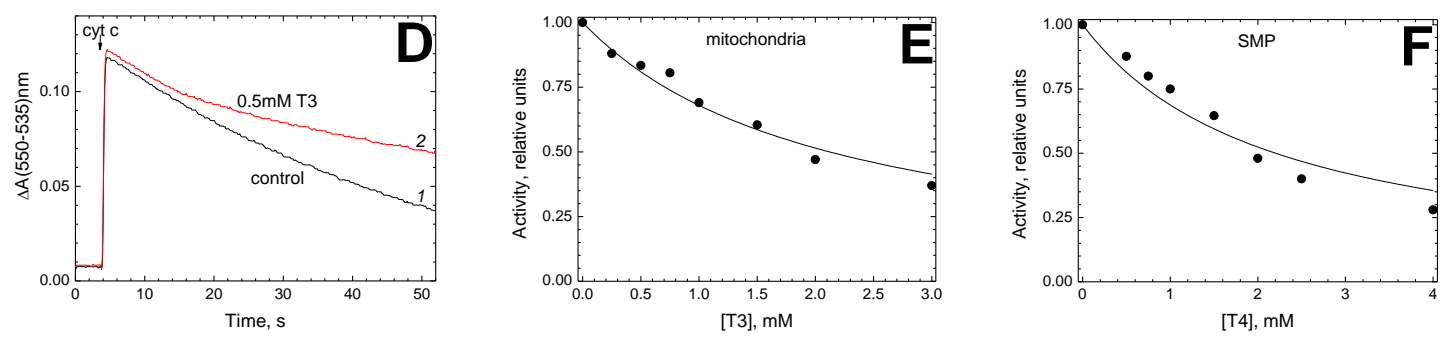

Figure 2. Inhibitory effect of thyroid hormones on the oxidase activity of the membrane incorporated CcO. (a), (b), (c) Titration of the oxidase activity of $\mathrm{CcO}$ in proteoliposomes by T3 (a), T4 (b) and T2 (c). The experimental medium was $50 \mathrm{mM}$ potassium-phosphate buffer $\mathrm{pH} 7.6$ supplemented with $0.1 \mathrm{mM}$ EDTA and $1 \mu \mathrm{M}$ CCCP. Proteoliposomes were added up to $26 \mathrm{nM} \mathrm{CcO}$. Oxidase reaction was initiated by addition of the respiratory substrate $(5 \mathrm{mM}$ ascorbate $+0.1 \mathrm{mM}$ TMPD $+10 \mu \mathrm{M}$ cytochrome $c$ ). Other details are as in Figure $1 \mathrm{~b}$, d. (d)T3-induced inhibition of ferrocytochrome $c$ oxidation by $\mathrm{CcO}$ in proteoliposomes. The activity was measured following oxidation of ferrocytochrome $c$ (see Section 2) in the absence (control curve 1, black) or in the presence (curve 2, red) of $0.5 \mathrm{mM}$ T3 in the medium. Other conditions are as in panel a except that proteoliposomes were added up to $3.25 \mathrm{nM} \mathrm{CcO}$. (e) Inhibitory effect of $\mathrm{T} 3$ on $\mathrm{CcO}$ oxidase activity in rat liver mitochondria. Rat liver mitochondria were suspended in the experimental medium (0.3 M sucrose, $50 \mathrm{mM}$ Hepes/Tris pH 7.6, $0.5 \mathrm{mM}$ EDTA, $0.5 \mu \mathrm{M} \mathrm{CCCP)} \mathrm{up} \mathrm{to}$ $0.8 \mathrm{mg}$ of protein $/ \mathrm{ml}$. Other details are as in Figure $1 \mathrm{~b}$, d. (f) Inhibitory effect of $\mathrm{T} 4 \mathrm{on} \mathrm{CcO}$ oxidase activity in SMP obtained from bovine heart mitochondria (see Section 2). Conditions are essentially as on panel e except that $\mathrm{CcO}$ concentration in the probe was $20 \mathrm{nM}$.

The effect of hormones T3, T4 and T2 on the oxygen consumption by proteoliposomes is shown in Figure 2 (panels a, b and c, respectively). Inhibition is observed with all hormones, however it affects only $50-60 \%$ of the activity. The data obtained in titration of the inhibitor-sensitive part of the activity fit well hyperbolic function (1) and give the Ki parameters: $0.19 \mathrm{mM}$ T3 (Figure 2a), $0.31 \mathrm{mM}$ T4 (Figure 2b) and $1.4 \mathrm{mM}$ T2 (Figure 2c) which are close enough to the values obtained for enzyme in solution (see above).

Figure $2 \mathrm{~d}$ illustrates oxidase activity of proteoliposomes registered by an alternative method, i.e. monitoring oxidation of the preliminary reduced cytochrome $c$ in the absence of ascorbate and TMPD. The decrease in absorption at $550 \mathrm{~nm}$ relative to $535 \mathrm{~nm}$ ( $\alpha$-band of the reduced cytochrome $c$ ) was followed. Pre-incubation of proteoliposomes with $0.5 \mathrm{mM}$ T3 for $30 \mathrm{~min}$ results in approximately twofold decrease in the activity as compared to the control, in full agreement with the data obtained on Oxygraph (see Figure 2b). Sufficient time resolution of the spectrophotometric measurements allows to notice that the starting reaction rates are completely identical in the control (curve 1) and after pre-incubation of the sample with T3 (curve 2). In the latter case, inhibition develops only after $10 \mathrm{~s}$ of enzyme activity in the presence of the hormone. It can be concluded that (i) the absence of ascorbate and TMPD do not affect inhibition, and (ii) only turning over enzyme is susceptible to inhibition.

Then, $\mathrm{CcO}$ in the native mitochondrial membrane was investigated. In Figure 2e, respiration of rat liver mitochondria has been monitored in the presence of $\mathrm{T} 3$ at various concentrations. Mitochondria were preliminarily exhausted in endogenous substrates and their outer membrane was partially destroyed which made it possible to use exogenous cytochrome $c$ as an electron donor. Cytochrome oxidase activity was found to be completely sensitive to $\mathrm{T} 3$ inhibition. The data obtained are well described by the hyperbolic function (1). The $\mathrm{T} 3$ induced inhibition of $\mathrm{CcO}$ in mitochondria is characterized by $K_{\text {i value }} 2.1 \pm 0.14 \mathrm{mM}$ which is 10 times higher than the values obtained for isolated enzyme $(0.22 \mathrm{mM}$, Figure $1 \mathrm{~b}, \mathrm{c})$ or proteoliposomes $(0.19 \mathrm{mM}$, Figure $2 \mathrm{a})$.

Similar results were obtained on the inhibition of submitochondrial particles (SMP) respiration by T4 (Figure 2f). As with mitochondria, complete inhibition was observed. The data fit well function (1) with $K_{\mathrm{i}}=2.2 \pm 0.2 \mathrm{mM}$ which is an order of magnitude higher than $K_{\mathrm{i}}$ values for enzyme in solution $(0.1$ $\mathrm{mM}$, Figure $1 \mathrm{~d}, \mathrm{e})$ or in proteoliposomes $(0.31 \mathrm{mM}$, Figure $2 \mathrm{~b})$. 
To determine which stages of intramolecular electron transfer are sensitive to thyroid hormones, the effect of T3 and T4 on the level and kinetics of heme reduction was studied (Figure 3). The oxidase reaction was carried out in a closed cuvette using ascorbate (as an electron source) in combination with the redox mediators $\mathrm{RuAm}$ or TMPD. The reduction of $\mathrm{CcO}$ was monitored spectrophotometrically.
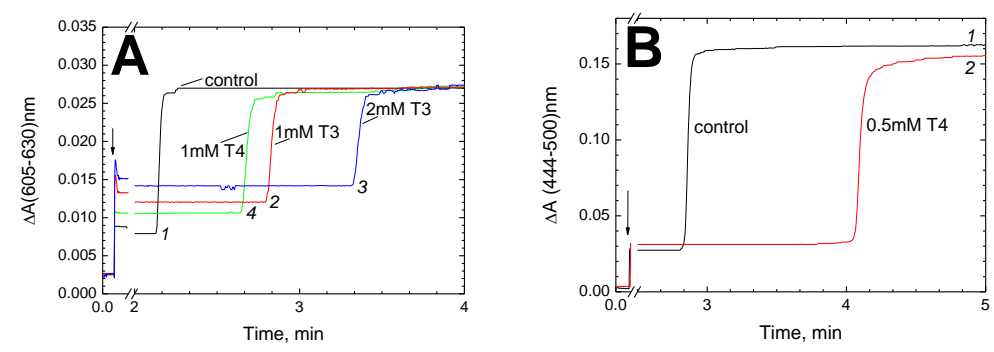

Figure 3. Hormones T3 and T4 decelerate electron transfer from heme $a$ to heme $a_{3}$. (a) Effect of T3 and T4 on the steady-state level of heme $a$ reduction. $\mathrm{CcO}(\mathrm{ca} .1 \mu \mathrm{M})$ in the Basic Medium pH 8.0 supplied with 5 $\mu \mathrm{M}$ RuAm and, where indicated, by T3 or T4 was placed in a closed cuvette and reduced by addition of 5 $\mathrm{mM}$ ascorbate (indicated by the arrow). Reduction level of heme $a$ was followed as absorption difference at (605-630) $\mathrm{nm}$ in the absence (control trace 1, black) or in the presence of $1 \mathrm{mM}$ T3 (trace 2, red), $2 \mathrm{mM} \mathrm{T3}$ (trace 3, blue) or $1 \mathrm{mM} \mathrm{T} 4$ (trace 4, green). (b) Effect of T4 on the kinetics of hemes $a$ and $a_{3}$ reduction upon the onset of anaerobiosis. Total reduction level of hemes $a$ and $a_{3}$ in the Soret region at (444-500) nm was registered. Trace 1, black - control, trace 2, red - reduction of the sample in the presence of $0.5 \mathrm{mM} \mathrm{T4}$. Other conditions are as in panel a except that $0.1 \mathrm{mM}$ TMPD was used as redox-mediator instead of RuAm.

Panel a presents the kinetics of absorption growth at $605 \mathrm{~nm}$ relative to $630 \mathrm{~nm}$ ( $\alpha$-absorption band with a contribution of heme $a$ about $80 \%$ [28]). The injection of the respiratory substrate (shown by an arrow) results in an instant increase of absorption up to a steady-state level of heme $a$ reduction in the turning over $\mathrm{CcO}$. After 2-3 minutes, the reduction sharply rises to $100 \%$ due to the depletion of oxygen. It can be seen that in the presence of T3 (1 mM, red curve 2, or $2 \mathrm{mM}$, blue curve 3$)$ or T4 (1 mM, green curve 4) anaerobiosis occurs later than in the control (black curve 1). It is explained by slowing down the enzyme activity by the inhibitor. Notably, the inhibitory effect of thyroid hormones on $\mathrm{CcO}$ does not require the presence of cytochrome $c$ and is also manifested in the oxidation of reduced TMPD or RuAm. In addition, the steady-state level of heme $a$ reduction in the presence of thyroid hormones is substantially higher than in the control: by $\sim 75 \%$ and $\sim 115 \%$ in $1 \mathrm{mM}$ and $2 \mathrm{mM}$ T3 (curves 2 , red and 3, blue) and by $~ 50 \%$ in $1 \mathrm{mM} \mathrm{T} 4$ (green curve 4). This indicates a slowdown of electrons escape from heme $a$ to heme $a_{3}$.

Panel $\mathrm{b}$ shows the kinetics of cumulative reduction of hemes $a$ and $a_{3}$ recorded as absorption growth at $444 \mathrm{~nm}$ relative to $500 \mathrm{~nm}$, at the $\gamma$-bands where the contributions of heme $a$ and $a_{3}$ to the absorption are approximately equal [28]). It can be noted that enzyme reduction upon the onset of anaerobiosis is clearly biphasic, which is consistent with the literature data. The rapid reduction of heme $a$ is followed by a much slower phase which is presumed to be associated mainly with the reduction of heme $a_{3}[29-31]$. As seen, the second phase corresponding to electron transfer to heme $a_{3}$ noticeably slows down in the presence of $0.5 \mathrm{mM}$ T4 (red curve 2) compared to the control (black curve 1). The values of $\mathrm{t}_{1 / 2}$ can be roughly estimated as $5.8 \mathrm{~s}$ and $0.9 \mathrm{~s}$, respectively.

\subsection{The effects of thyroid hormones on the $\mathrm{CcO}$ partial activities associated with the peroxidase phase of catalytic cycle}

It was shown [32] that the presence of $\mathrm{H}_{2} \mathrm{O}_{2}$ enables $\mathrm{CcO}$ to operate within a truncated peroxidase cycle bypassing the eu-oxidase phase of the reaction. The reaction of $\mathrm{CcO}$ with excess hydrogen peroxide results in the sequential formation of oxoferryl intermediates which are similar in structure to the intermediates $\mathrm{F}_{\mathrm{I}}-607$ and $\mathrm{F}_{\mathrm{II}}-580$ registered in the oxygen reduction cycle by the rapid kinetic techniques (see reviews $[1,2,7,33]$ ). The sequence of $\mathrm{Ox} \rightarrow \mathrm{FI}_{\mathrm{I}}-607 \rightarrow \mathrm{F}_{\mathrm{II}}-580 \rightarrow \mathrm{Ox}$ (where Ox designates the free oxidized state of the binuclear center) transformations in the reaction of $\mathrm{CcO}$ with $\mathrm{H}_{2} \mathrm{O}_{2}$ was described as a "pseudocatalase cycle" in which one $\mathrm{H}_{2} \mathrm{O}_{2}$ molecule bound in the binuclear center is reduced to water 
(peroxidase reaction) by electrons coming from the other $\mathrm{H}_{2} \mathrm{O}_{2}$ molecule which decays in a catalase-type reaction to superoxide converted after dismutation to $\mathrm{H}_{2} \mathrm{O}_{2}$ and $\mathrm{O}_{2}$ [34]. The reactions of formation and transformation of oxoferryl intermediates make the basis for the partial redox activities catalyzed by $\mathrm{CcO}$ : peroxidase, catalase and generation of superoxide.

\subsubsection{Thyroid hormones do not inhibit the $\mathrm{CcO}$ peroxidase activity}

As shown recently $[14,15]$ a number of steroid hormones and structurally similar compounds are effective inhibitors of the oxidase activity of $\mathrm{CCO}$ from mitochondria but at the same time do not affect the peroxidase reaction catalyzed by the enzyme. The data below show that none of the thyroid hormones $\mathrm{T} 2, \mathrm{~T} 3$, and $\mathrm{T} 4$ inhibits the peroxidase activity of mitochondrial $\mathrm{CcO}$.

As demonstrated in [32], aerobic registration of the peroxidase activity of $\mathrm{CcO}$ requires highpotential $\left(\mathrm{E}_{0} \geq+400 \mathrm{mV}\right.$ ) electron donors. Oxidation of such compounds is possible due to the participation of oxoferryl intermediates $\mathrm{F}_{\mathrm{I}}-607$ and $\mathrm{F}_{\mathrm{II}}-580$ as final acceptors since their one-electron redox transitions are characterized by Eo' around $1 \mathrm{~V}[35,36]$. As we have shown earlier, one of the typical peroxidase substrates, $o$-dianisidine serves also as an effective donor for $\mathrm{CcO}$ in the peroxidase reaction [37]. However, we found $o$-dianisidine to be inapplicable in the present investigation because its interaction with $\mathrm{CcO}$ was severely impaired in the presence of thyroid hormones (data not shown). Therefore, we used as an electron source ferro-ferricyanide redox pair with a potential of $\sim+420 \mathrm{mV}$. The reaction was followed by formation of ferricyanide (increase in absorption at $420 \mathrm{~nm}$ ). A typical experiment is shown in Figure 4.

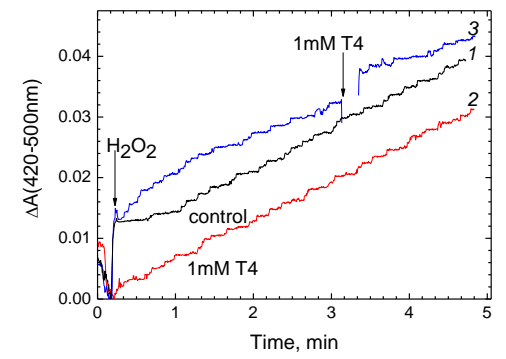

Figure 4. Peroxidase reaction catalyzed by $\mathrm{CcO}$ is not affected by thyroid hormones. Peroxidation of ferrocyanide was monitored by increase of absorption at $420 \mathrm{~nm}$ vs $500 \mathrm{~nm}$ reference. The redox buffer was ferro/ferricyanide (1:1) mixture. The Basic Medium pH 7.6 contained additionally $0.2 \mathrm{mM}$ ferrocyanide, $0.2 \mathrm{mM}$ ferricyanide and $0.6 \mu \mathrm{M} \mathrm{CcO}$. No oxidation of ferrocyanide by oxygen was observed and peroxidase reaction was triggered by addition of $4 \mathrm{mM} \mathrm{H}_{2} \mathrm{O}_{2}$ (shown by the arrow). Trace 1, blackcontrol, trace 2, red - the experiment in the presence of $1 \mathrm{mM} \mathrm{T4}$, trace 3, blue $-1 \mathrm{mM}$ T4 was added in the course of the experiment, as indicated by the arrow. The initial jump upon $\mathrm{H}_{2} \mathrm{O}_{2}$ addition reflects spectral response in $\gamma$-band of heme $a_{3}$ upon oxoferryl intermediates formation.

As seen, addition of $1 \mathrm{mM}$ T4 to the medium before the start of the reaction (red curve 2) as well as in its course (blue curve 3) does not change noticeably the rate of ferrocyanide peroxidation compared to the control (black curve 1). Similar results were obtained with $\mathrm{T} 3$ and $\mathrm{T} 2$ hormones. The respective rates of peroxidase reaction were: $0.19 \mathrm{e} / \mathrm{s}$ (control), $0.21 \mathrm{e} / \mathrm{s}$ (in the presence of $0.5 \mathrm{mM} \mathrm{T2}$ ), $0.24 \mathrm{e} / \mathrm{s}$ (in the presence of $0.5 \mathrm{mM} \mathrm{T} 3$ ) and $0.22 \mathrm{e} / \mathrm{s}$ (in the presence of $0.5 \mathrm{mM} \mathrm{T} 4$ ), with the measurement error about $10 \%$.

3.3.2. Thyroid hormones do not inhibit the catalase activity of $\mathrm{CcO}$ 
Figure 5 shows the effect of thyroid hormones on the catalase activity of $\mathrm{CcO}$.

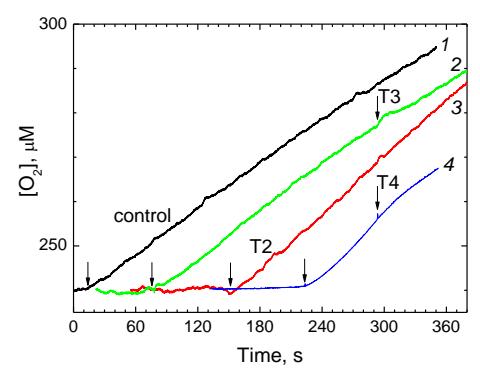

Figure 5. Thyroid hormones do not inhibit catalase activity of $\mathrm{CcO}$. Catalase activity was registered by oxygen production with the aim of Clark-type electrode according to [26]. The addition of $12 \mathrm{mM} \mathrm{H}_{2} \mathrm{O}_{2}$ into the experimental medium (30 mM potassium phosphate buffer $\mathrm{pH} 7.1,2 \mathrm{mM}$ EDTA, 0.05\% DM) did not induce any detectable oxygen release. The catalase reaction was initiated by addition of $1.5 \mu \mathrm{M} \mathrm{CcO}$, as indicated by the vertical arrows. Trace 1, black - control, traces 2-4 - thyroid hormones (T3 - 2, green, T2 - 3, red, T4 -4 , blue). T2 was pre-added up to $0.5 \mathrm{mM}$, T3 and T4 were added up to $0.5 \mathrm{mM}$ and $1 \mathrm{mM}$, respectively, as marked by the arrows.

The decay of peroxide was recorded on Oxygraph by oxygen evolution. Addition of $12 \mathrm{mM} \mathrm{H}_{2} \mathrm{O}_{2}$ to the medium did not induce a noticeable oxygen release. The reaction was triggered by addition of $\mathrm{CcO}$ after which the $\mathrm{O}_{2}$ concentration in the medium began to increase at a constant rate. Addition of any thyroid hormone $(0.5 \mathrm{mM} \mathrm{T} 2, \mathrm{~T} 3$ or T4) into the assay medium preliminary as well as in the course of the reaction did not affect significantly the rate of $\mathrm{O}_{2}$ release. The following experimental curves are shown for illustration: 1 (black) - control, 2 (green) - with $0.5 \mathrm{mM}$ T3 added in the course of the experiment, 3 (red) - with $0.5 \mathrm{mM} \mathrm{T} 2$ added preliminary, 4 (blue) - with $1 \mathrm{mM} \mathrm{T} 4$ added in the course of the experiment. Higher hormone concentrations (curve 4) caused a slight suppression of the activity not exceeding $10-20 \%$.

\subsubsection{Thyroid hormones slightly accelerate the formation of intermediate $\mathrm{F}_{\mathrm{II}}-580$}

Intermediates $\mathrm{FI}_{\mathrm{I}}-607$ and $\mathrm{F}_{\mathrm{II}}-580$ differ in position of their absorption bands in the difference spectra against free enzyme (the peaks at $607 \mathrm{~nm}$ and $580 \mathrm{~nm}$, respectively). Thus, it is convenient to monitor their formation spectrophotometrically during titration of the oxidized $\mathrm{CcO}$ with increasing concentrations of peroxide [38 - 41]. In the micromolar concentration range, $\mathrm{H}_{2} \mathrm{O}_{2}$ induces a gradual complete transition of free enzyme to a mixture of oxoferryl states with a predominance of $\mathrm{F}_{\mathrm{I}}-607$ form. At higher $(>1 \mathrm{mM})$ concentrations of $\mathrm{H}_{2} \mathrm{O}_{2}, \mathrm{~F}_{\mathrm{I}}-607$ decays and is partially replaced by $\mathrm{F}_{\mathrm{II}}-580$. We tried to evaluate the effects of thyroid hormones on the steady-state equilibrium of oxoferryl intermediates during the titration of the oxidized enzyme with peroxide. Indeed, in the presence of $0.5 \mathrm{mM} \mathrm{T} 3$ or T4 a small (within 15\% -25\%) but reproducible decrease in the quasi-stationary concentration ratio [FI-607]/[FII580] was observed, as compared to the control (data not shown).

Qualitatively, the same result was obtained upon rapid mixing of oxidized $\mathrm{CcO}$ with hydrogen peroxide in a stopped-flow device. The set of spectral data was collected with a photodiode array. Figure 6 shows the results obtained after mixing of $1 \mathrm{mM} \mathrm{H}_{2} \mathrm{O}_{2}$ with $3.25 \mu \mathrm{M} \mathrm{CcO}$ in the presence or absence of $0.5 \mathrm{mM}$ T4 (hereinafter, the final concentrations after mixing are presented).
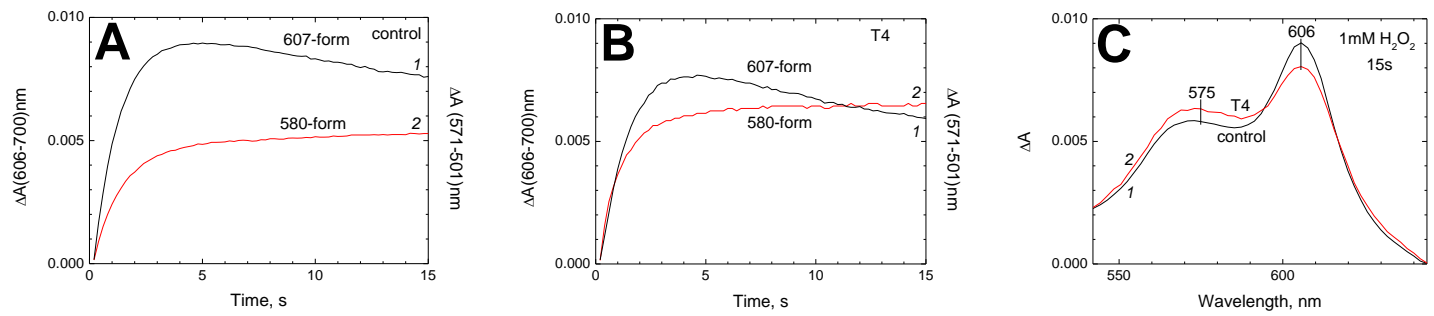

Figure 6. The effect of $\mathrm{T} 4$ on the formation of $\mathrm{CcO}$ oxoferryl intermediates during the reaction with $\mathrm{H}_{2} \mathrm{O}_{2}$. The reaction was followed upon rapid mixing of $\mathrm{CcO}$ with hydrogen peroxide in the presence or in the absence of T4 using diode array spectrophotometer SX-20 (see Section 2). The medium (Basic Medium pH 8.1 supplied with $0.1 \% \mathrm{DM}$ ) contained additionally ferricyanide to maintain the enzyme in oxidized state. 
Final concentrations after mixing: $3.25 \mu \mathrm{M} \mathrm{CcO}, 50 \mu \mathrm{M}$ ferricyanide, $1 \mathrm{mM} \mathrm{H}_{2} \mathrm{O}_{2}, 0.5 \mathrm{mM}$ T4. (a, b) Kinetics of the oxoferryl intermediates formation. Spectral forms FI-607 (traces 1, black) and FII-580 (traces 2 , red) were followed by absorption difference at (606-700) $\mathrm{nm}$ and at (571-501) $\mathrm{nm}$, respectively. a control, b- CcO was pre-incubated with $0.5 \mathrm{mM}$ T4 untill mixing. (c) Difference spectra (15 s vs $0.2 \mathrm{~s}$ after mixing) obtained in the absence (control spectrum 1, black) and in the presence (spectrum 2, red) of 0.5 mM T4.

Panels a (control) and b (experiment in the presence of T4) show kinetic traces of FI-607 and FII580 formation monitored, respectively, as the absorbance difference at $606 \mathrm{~nm} v s 700 \mathrm{~nm}$ reference, and $571 \mathrm{~nm}$ vs $501 \mathrm{~nm}$ reference. In the presence of T4, FI-607 forms slightly slower ( $\left.\mathrm{t}_{1 / 2} \approx 0.99 \mathrm{~s} v \mathrm{~s} 0.91 \mathrm{~s}\right)$ and its yield is lower than in the control ( $c f$. black curves 1 in panels a and b), whereas the formation of $F_{\text {II }}-580$ is accelerated by $23 \%\left(\mathrm{t}_{1 / 2} \approx 0.85 \mathrm{~s} v s 1.1 \mathrm{~s}\right)$ and the yield is higher than in the control (cf. red curves 2 in panels a and b). Figure $6 \mathrm{c}$ shows the difference absorption spectra of the control sample (spectrum 1) and the sample treated with T4 (spectrum 2) obtained $15 \mathrm{~s}$ after mixing (absolute spectra recorded $0.2 \mathrm{~s}$ after mixing are subtracted). At the $15^{\text {th }}$ second, the observed difference is most evident. As seen, in the presence of T4 the concentration of $\mathrm{F}_{\mathrm{I}}-607$ is lower, and $\mathrm{F}_{\mathrm{II}}-580$ higher than in the control, though the deviation is only about $10 \%$. Accordingly, the overall decrease of the ratio [FI-607]/[FII-580] consists about $20 \%$, exactly as in the titration experiments (see above).

\subsection{Thyroid hormones strongly inhibit the generation of superoxide anions by $\mathrm{CcO}$}

The release of superoxide in the pseudocatalase cycle was confirmed experimentally by EPR [42] and with tetrazolium salts as a probe for $\mathrm{O}_{2}{ }^{\bullet-}$ [27]. The kinetics of superoxide production by $\mathrm{CcO}$ registered by the reduction of water-soluble tetrazolium WST-1 as absorption difference at (442-552) nm is shown in Figure 7a.
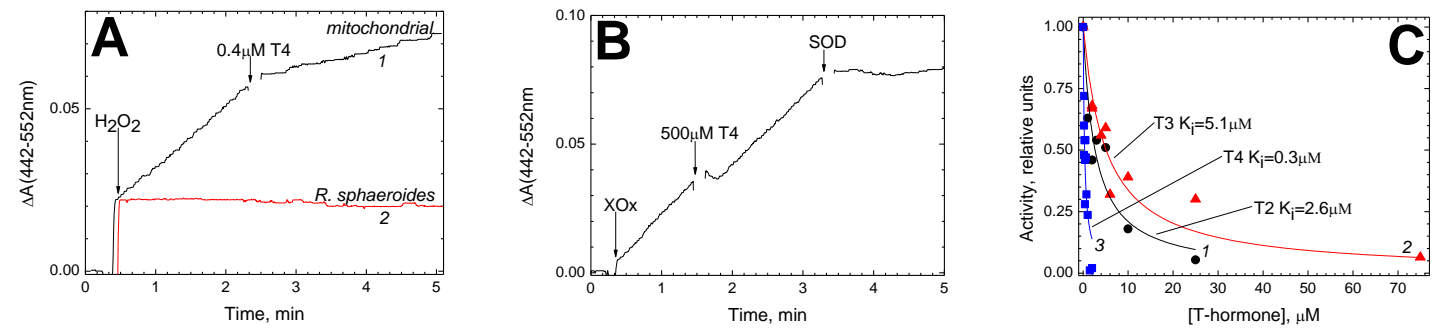

Figure 7. Thyroid hormones strongly inhibit superoxide generation by $\mathrm{CcO}$ in the presence of excess $\mathrm{H}_{2} \mathrm{O}_{2}$. (a) A typical kinetics of superoxide production catalyzed by mitochondrial $\mathrm{CcO}$ (trace 1, black) as compared to bacterial aa3-type oxidase from R. sphaeroides (trace 2, red). Addition of $0.4 \mu \mathrm{M} \mathrm{T} 4$ is indicated. $\mathrm{CcO}$ was added up to $0.5 \mu \mathrm{M}$ into the Basic Medium, pH 7.6 containing $0.1 \mathrm{mM}$ WST-1. The reaction was initiated by addition of $4 \mathrm{mM} \mathrm{H}_{2} \mathrm{O}_{2}$ (indicated by the arrow). Reduction of the dye was registered by absorbance difference at (442-552) $\mathrm{nm}$. (b) T4 has no superoxide dismutase activity. Superoxide formation accompanying the oxidation of hypoxanthine $(50 \mu \mathrm{M})$ by xanthine oxidase $(\mathrm{XOx}, 0.015 \mathrm{units} / \mathrm{ml})$ was followed as in panel a. Additions of $500 \mu \mathrm{M}$ T4 and superoxide dismutase (SOD, $20 \mu \mathrm{g} / \mathrm{ml}$ ) are shown by the arrows. (c) Concentration dependence of the inhibitory effect of thyroid hormones (T2 - black circles, $\mathrm{T} 3$ - red triangles and T4 - blue squares) on superoxide production by mitochondrial $\mathrm{CcO}$. Conditions of the measurements are as in panel a. Activity (the ratio of the reaction rate after the onset of inhibition to the initial reaction rate) is given in relative units. Experimental data are approximated by function (1) drawn in appropriate colors, with different values of the $\mathrm{K}_{\mathrm{i}}$ parameter (indicated).

The reaction was started by addition of $4 \mathrm{mM} \mathrm{H}_{2} \mathrm{O}_{2}$. The instantaneous increase in absorption immediately after the peroxide addition is associated with the transition of $\mathrm{CcO}$ to the oxoferryl state. Then, the reduction of the dye proceeds at a constant rate which drops threefold after addition of $0.4 \mu \mathrm{M}$ T4 (curve 1, black). In contrast to mitochondrial enzyme, $\mathrm{CcO}$ from $R$. sphaeroides does not generate $\mathrm{O}_{2}{ }^{\bullet-}$ under the same conditions (curve 2, red).

To probe whether the suppression of WST reduction in Figure 7a is due to superoxide dismutase activity of T4, we tested the effect of T4 on superoxide generation by xanthine oxidase oxidizing hypoxanthine (Figure $7 \mathrm{~b}$ ). The conditions were adjusted so that the rate of WST reduction was 
approximately the same as in panel a. As seen in Figure $7 \mathrm{~b}$, the addition of $500 \mu \mathrm{M}$ T4 does not affect the rate of dye reduction, but, as expected, the process is completely blocked by superoxide dismutase.

Similar results are obtained with hormones T2 and T3. The concentration dependences of the inhibition of $\mathrm{O}_{2}{ }^{\bullet-}$ generation by thyroid hormones are shown in Figure 7c. All three hormones induced a complete inhibition of the reaction, and the experimental data fit well function (1). The $K_{\mathrm{i}}$ values obtained by approximation are: $2.6 \mu \mathrm{M} \mathrm{T} 2$ (curve 1, black), $5.1 \mu \mathrm{M}$ T3 (curve 2, red), and $0.3 \mu \mathrm{M}$ T4 (curve 3, blue).

\section{Discussion}

As we have found recently, a number of steroid hormones (estradiol, testosterone, dehydroepiandrosterone, progesterone), as well as the compounds related to them in chemical structure (the secosteroids cholecalciferol and ergocalciferol) or even resembling them spatially (Triton X-100) have a pronounced inhibitory effect on solubilized $\mathrm{CcO}$ from mitochondria $[14,15]$. The characteristic features of the inhibition are as follows:

(1) the $K_{\mathrm{i}}$ values in the range of $10^{-5}-10^{-4} \mathrm{M}$;

(2) an 1:1 stoichiometry competition between the inhibitor and the detergent DM which increases the apparent $K_{\mathrm{i}}$ values;

(3) slowing down the electron transfer from heme $a$ to the oxidized binuclear center;

(4) resistance of the partial $\mathrm{CcO}$ activities associated with the peroxidase phase of the catalytic cycle to inhibitor concentrations sufficient for almost complete suppression of the oxidase reaction.

We interpreted the above facts as evidence that steroid hormones and their analogs are ligands of the BABS site located in the mouth of the K-proton channel, and their inhibitory effect is associated with impair in conductivity of this channel. Hormone binding arrests those stages of the catalytic cycle at which channel $\mathrm{K}$ is active (eu-oxidase phase of the cycle), while the stages at which it is closed (peroxidase phase of the cycle) remain unaffected. From this point of view, the effect of steroid-like inhibitors resembles the result of mutations on the key K-channel residues in $\mathrm{CcO}$ from $R$. sphaeroides [43, 44]. We also assumed that DM in our experiments substitutes an endogenous phospholipid molecule that is tightly bound near BABS and partially overlaps with it in some conformations [9, 11]. It can be suspected that the affinity of the enzyme for the physiological inhibitor might be modulated in vivo just in this way.

Thus, we got the impression that physiological ligands of BABS in mitochondrial $\mathrm{CcO}$ are steroids. Considering this possibility, we established that the values of $K_{i}$ obtained under our conditions (from $9 \mu \mathrm{M}$ for cholecalciferol to $0.37 \mathrm{mM}$ for estradiol, about $100 \mu \mathrm{M}$ on average) fairly fall within the range of possible intramembrane concentrations of steroid hormones in vivo, taking into account their content in blood serum (ca. 10-8 M [45 - 47]) and the distribution coefficient between hydrophobic and water phases (ca. $10^{4}$ [48-Shoshtari 2008]). The relevance of our data is also confirmed by the acting concentrations of steroid hormones $\left(10^{-4}-10^{-3} \mathrm{M}\right)$ used in the experimental studies on cell cultures [4953].

The data presented in this work indicate that thyroid hormones are able, like steroids, to interact with mitochondrial $\mathrm{CcO}$ at BABS and modulate the enzyme activity. Indeed, thyroid hormones T3 and T4 effectively inhibit the oxidase activity of solubilized enzyme with $K_{\mathrm{i}}$ about $200 \mu \mathrm{M}$ and $100 \mu \mathrm{M}$, respectively (Figure 1c, e), and the apparent $K_{i}$ values increase with an increase in the DM concentration. Inhibition data analysis points the competition between DM and inhibitor in a 1:1 ratio and, noteworthy, predicts dissociation constant for the DM-CcO complex to be about $1.1 \mathrm{mM}$ (see the $K_{\mathrm{c}}$ value in Figure $1 \mathrm{c}$ and e). The latter is rather close to the values obtained earlier in the studies on $\mathrm{CcO}$ inhibition by estradiol and testosterone $\left(K_{\mathrm{c}}=1.47 \mathrm{mM}\right.$ and $1.3 \mathrm{mM}$, respectively) [14], and by Triton X-100 $\left(\mathrm{K}_{\mathrm{c}}=1.2 \mathrm{mM}\right)$ [15]. This coincidence is a serious indication that thyroid and steroid hormones bind to $\mathrm{CcO}$ at the same place, namely, in the region where the enzyme affinity for DM is characterized by dissociation constant of $1-1.5$ $\mathrm{mM}$.

Like steroids, thyroid hormones $\mathrm{T} 3$ and $\mathrm{T} 4$ do not inhibit the partial $\mathrm{CcO}$ activities associated with the peroxidase phase of the enzyme cycle. At concentrations sufficient for almost complete suppression of the oxidase activity, hormones T3 and T4 do not reduce the peroxidase activity of $\mathrm{CcO}$ (see Figure 4 which demonstrates the complete resistance of peroxidase activity to $1 \mathrm{mM}$ T4 that is $5 \mathrm{~K}_{\mathrm{i}(\mathrm{app})}$ 
under conditions of the experiment, see Figure 1e). The catalase activity of $\mathrm{CcO}$ is also actually insensitive to the action of $\mathrm{T} 3$ and $\mathrm{T} 4$ at concentrations of $0.5-1 \mathrm{mM}$ (Figure 5).

The generation of superoxide is another partial reaction associated with the peroxidase phase of $\mathrm{CcO}$ catalytic cycle, and it worth separate mentioning. This activity is not affected at all by sex steroid hormones (unpublished data), while thyroid hormones, unexpectedly, inhibit it with high specificity (Figure 7). The reaction conditions however suggest that in the latter case $\mathrm{O}_{2}{ }^{\bullet-}$ is formed on the enzyme surface rather than in the binuclear center (see below for the details).

At the same time, a small but reliable effect of $0.5 \mathrm{mM}$ T3 and $\mathrm{T} 4$ on the interconversion of intermediates $\mathrm{FI}_{\mathrm{I}}-607$ and $\mathrm{FIII}_{\mathrm{II}} 580$ formed in the reaction of $\mathrm{CCO}$ with peroxide has been registered both by steady-state titrations and rapid mixing technique (Figure 6). It manifests mainly in a 20-25\% accelerated formation of an intermediate with spectral properties of form 580 (compare red curves 2 in Figure 6a and b). As seen in Figure 6b, during the first second of the rapid mixing experiment the kinetics of the appearance of two oxoferryl forms in the presence of $0.5 \mathrm{mM}$ T4 coincides. This allow to propose that intermediates with absorption maxima at $607 \mathrm{~nm}$ and $580 \mathrm{~nm}$ are not formed in this case in the $\mathrm{Ox} \rightarrow 607$ $\rightarrow 580$ sequence as in the control (Figure 6a), but rather synchronously from Ox. Therefore, we hypothesize that in the presence of T4 at least part of the observed "form 580" represent actually intermediate-I isoelectronic to $\mathrm{F}_{\mathrm{I}}-607$ but spectrally similar to $\mathrm{F}_{\mathrm{II}}-580$. Our interpretation is clearly supported by the fact that the yield of spectral "form 607" (black curve 1) in the presence of T4 looks noticeably lower, and that of spectral "form 580" (red curve 2) higher than in the control. The specific kind of intermediate-I with broad absorption band around 570-580 $\mathrm{nm}$ is known as the "acidic" form, or $\mathrm{F}^{\prime}$ [54], or $\mathrm{F}^{\bullet}$ [55], or F-I 575 [56]. It is observed during the reaction of $\mathrm{CcO}$ with peroxide at acidic $\mathrm{pH}$ and is believed to differ spectrally from $\mathrm{F}_{\mathrm{I}}-607$ due to protonation of a certain group near the binuclear center [55]. It is of interest that K362M replacement of the key residue in the K-channel makes spectral properties of intermediate-I $\mathrm{pH}$-independent [56]. It can be assumed that $\mathrm{T} 3$ or T4 binding at BABS changes the structure of hydrogen bonds in the K-channel which leads to protonation of the group that determines spectral properties of intermediate-I. Note however that the observed effect is not large: $\mathrm{F}_{\mathrm{I}}$ $607 / \mathrm{F}_{\mathrm{II}}-580$ ratio in the presence of $0.5 \mathrm{mM}$ T3 or T4 changes by no more than $20 \%$ compared to the control (see Figure 6c).

At the same time, thyroid hormones T3 and T4 inhibit transfer of the first two electrons to the oxidized binuclear center, the process related to the eu-oxidase part of catalytic cycle. Firstly, this is indirectly evidenced by an increase in the steady-state level of heme $a$ reduction while enzyme is operating in the presence of T3 or T4 (Figure 3a). It can be explained by the slower escape of an electron from heme $a$ to the binuclear center. Secondly, hormones T3 and T4 noticeably affect the kinetics of CcO reduction during the onset of anaerobiosis (Figure $3 b$ ). The total reduction of the hemes during the transition of the enzyme to completely reduced state is a two-phase process, with the fast phase corresponding mainly to the reduction of heme $a$, and the slow phase - to the reduction of heme $a_{3}$ [29]. In the presence of $\mathrm{T} 3$ or $\mathrm{T} 4$ the slow component of hemes reduction decelerates noticeably which indicates inhibition of electron transfer to heme $a_{3}$.

Thus, thyroid hormones T3 and T4 exhibit the same properties of K-channel inhibitors as steroid hormones [14]. Currently we believe that both are ligands of BABS and serve as physiological regulators of mitochondrial $\mathrm{CcO}$. In contrast, the thyroid hormone $\mathrm{T} 2$ though also inhibiting oxidase activity differs drastically from T3 and T4 in its effect on the enzyme. Firstly, the effective T2 concentrations are tens of times higher (the formal $K_{\mathrm{i}(a p p)}$ value is $5.22 \pm 0.5 \mathrm{mM}$ ). Secondly, and extremely significant, the sensitivity to T2 does not depend on the DM concentration (compare open and filled symbols in Figure 1f), and moreover, even the replacement of detergent with Tween 20 does not in any way change the effective T2 concentration. The competition of the inhibitor with DM which apparently binds at the border of BABS seems to be evidence that the inhibitor itself binds to this particular site. Third, it turned out that the inhibitory effect of $\mathrm{T} 2$ on oxidase activity strongly depends on the enzyme concentration in the assay: a decrease in $\mathrm{CcO}$ concentration by $40-50$ times causes a decrease in the formal $\mathrm{K}_{\mathrm{i}(\mathrm{app})}$ value from $5.22 \mathrm{mM}$ to $0.89 \mathrm{mM}$. Note that in the case of T3 and T4 such a difference is not observed. The dependence of the inhibitory effect on the enzyme concentration can be associated with the multiple modes of interaction between $\mathrm{T} 2$ and $\mathrm{CcO}$. Thus, T2-induced effect appears to be non-specific. It should be concluded that the T2 hormone despite its chemical similarity with T3 and T4 is not a BABS ligand. Conspicuously, the 
presence of at least one iodine substituent in the second ring of the ligand molecule is critically important for the interaction of thyroid hormones with BABS. It is of interest that the pharmacological use of the "classical" thyroid hormones T3 and T4 is limited by their toxic effects (especially on the heart) which are much less pronounced in 3,5-diiodo-thyronine [19]. It can be assumed that among other reasons, the lower toxicity of $\mathrm{T} 2$ may be associated with its inability to modulate the $\mathrm{CcO}$ activity as a ligand of BABS.

The most crucial question that still remains obscure is the nature of the main BABS ligand in vivo. We are currently considering two possibilities. First, the "true" BABS ligand, physiological regulator of $\mathrm{CcO}$ activity could be still unknown. This might be a compound of mitochondrial membrane being lost during the isolation and purification of the enzyme. Comparison of the $\mathrm{CcO}$ sensitivity to thyroid hormones in solution and in mitochondrial membrane suggests that native environment of the enzyme makes it significantly less sensitive to inhibitor. Thus, the $K_{\mathrm{i}(a p p)}$ value for $\mathrm{T} 3 \mathrm{is}$ an order of magnitude higher in the whole mitochondria $(2.12 \mathrm{mM}$, see Figure $2 \mathrm{e})$ than in the solubilized enzyme $(0.22 \mathrm{mM}$, see Figure 1c). A modulating effect on the $\mathrm{CcO}$ sensitivity to the hormone is evidently exerted by some component of the membrane rather than mitochondrial matrix since a similar increase in $K_{\mathrm{i}(\text { app })}(2.2 \mathrm{mM}$, Figure $2 \mathrm{f}$ vs $0.1 \mathrm{mM}$, Figure 1e) is observed in SMP (closed membrane particles containing respiratory chain components in an "in-side-out" orientation). It should be noted that the placement of $\mathrm{CcO}$ in the membrane environment by itself does not cause a noticeable change in the effective concentrations of T3 and $\mathrm{T} 4$ as compared with enzyme in solution: the formal $K_{\mathrm{i}}$ values for T3 and T4 in azolectin proteoliposomes are $0.19 \mathrm{mM}$ and $0.31 \mathrm{mM}$, respectively (see Figure $2 \mathrm{a}$ and b). The twofold decrease in the inhibition depth observed on proteoliposomes is associated presumably with the heterogeneity of the preparation and in particular with the presence of multilayer liposomes. Although the time required in such a system for equilibration by the thyroid hormone concentration is unknown, the entry of T3 and T4 into the inner layers is expected to be rather slow due to high lipophilicity of these molecules. On the other hand, the fraction of enzyme trapped in the inner layers can contribute to oxidase activity due to the oxidation of TMPD which easily penetrates membranes. This enzyme fraction might occur to be inaccessible for inhibition within the period of the activity registration. It is all the more possible because, as it turned out, only a working enzyme is sensitive to inhibition by thyroid hormones T3 and T4. This is clearly seen from Figure $2 \mathrm{~d}$ where inhibition of the oxidase activity in the presence of $0.5 \mathrm{mM}$ T3 becomes noticeable only $\sim 10 \mathrm{~s}$ after triggering the reaction (which is about 450 catalytic cycles of the enzyme under the conditions of the experiment).

The observed change in the $\mathrm{CcO}$ sensitivity to the inhibition by $\mathrm{T} 3$ and $\mathrm{T} 4$ in the mitochondrial membrane could be explained by the competition of the thyroid hormone with an unknown endogenous ligand of BABS. However, another explanation is also possible. Dodecyl-maltoside which in experiments on the isolated enzyme significantly modulates the affinity of BABS to steroid-like ligands and thyroid hormones T3 and T4 is, as we think, an analogue of a natural lipid [57]. Indeed, a molecule of tightly bound phospholipid is present in 3D structures of mitochondrial $\mathrm{CcO}$ in the immediate vicinity of $\mathrm{BABS}$ [9], whereas in the enzyme from R. sphaeroides a similar place is occupied by the exogenous decylmaltoside molecule, the alkyl tail of which lies in the groove between subunits I and II, and the maltoside group is able to partially overlap with the putative binding site of amphipathic ligands [11]. We believe that the competition between hormones-inhibitors and DM mimics the natural situation in which a tightly bound endogenous phospholipid controls (by change in conformation and, as a result, the area of overlap with BABS) the effective affinity of BABS to physiologically active amphipathic ligands. The conformation of such a regulatory molecule can, in turn, depend on numerous factors, in particular, on the immediate molecular environment of the enzyme. It is possible that under the conditions of our experiments on mitochondria and on SMP the tightly bound phospholipid interacts quite strongly with BABS preventing hormone binding. As a result the affinity of the hormones for the enzyme decreases by an order of magnitude compared to the situation in solution or in proteoliposomes. It is not excluded that in vivo the lipid molecule can assume a different conformation which results in much more efficient binding of the regulating hormones to BABS. In light of these considerations, the second and, in our opinion, more exciting hypothesis about the native BABS ligand is that the site is capable to interact with a fairly wide range of amphipathic compounds many of which including steroid and thyroid hormones are physiological regulators of $\mathrm{CcO}$. 
Signaling pathways that determine the action of thyroid and steroid hormones in the cell intersect [16 - 19]. Interaction with $\mathrm{CCO}$ at BABS could represent the physical point of such an intersection. We believe that the multispecificity of BABS which apparently can also be referred to bacterial $\mathrm{CcO}$ may indicate the ancient origin of the regulatory mechanism based on the direct interaction between the key enzyme of oxidative phosphorylation and physiologically active agents which subsequently, in the course of evolution became regulators of high hierarchy.

Quite unexpectedly, it turned out that thyroid hormones inhibit with high specificity the generation of superoxide catalyzed by mitochondrial $\mathrm{CcO}$ in the presence of excess peroxide. This phenomenon is determined not by dismutase activity as one might suspect since thyroid hormones do not reduce the level of superoxide released during the oxidation of hypoxanthine by xanthinoxidase (Figure $7 \mathrm{~b}$ ). Inhibition of superoxide formation by thyroid hormones is fundamentally different from the suppression of oxidase activity by hormones-ligands of BABS in two aspects: (i) inhibition is induced not only by $\mathrm{T} 3$ and T4, but also and to no less extent by T2 hormone; (ii) the effective concentrations of hormones are two to three orders of magnitude lower ( $K_{\mathrm{i}}$ values are $2.6 \mu \mathrm{M}$ for T2, 5.1 $\mu \mathrm{M}$ for T3 and 0.3 $\mu \mathrm{M}$ for $\mathrm{T} 4$ - see Figure 7c). These differences allow us to conclude that the inhibitory effect of $\mathrm{T} 2, \mathrm{~T} 3$, and $\mathrm{T} 4$ on superoxide generation is associated not with BABS but with some other site of interaction characterized by a much higher affinity for thyroid hormones. In this regard, it should be remembered that $\mathrm{O}_{2}{ }^{--}$molecules formed in reaction of oxidized $\mathrm{CcO}$ with peroxide may originate from more than one source. Firstly, they are released by the binuclear center at the stages of the pseudocatalase cycle which correspond to the transformations FI-607 $\rightarrow$ FII-580 and FII-580 $\rightarrow$ Ox (see Scheme 1 in [34]). Secondly, according to [58], the lipid-based (or probably amino acid-based) radicals occur at the surface of $\mathrm{CcO}$ upon its interaction with peroxide, and these groups become another site of peroxide decomposition. It is assumed that such free radicals appear after a certain number of the pseudocatalase cycle turnovers as a result of the migration of an electron vacancy which appeared initially near the binuclear center to the protein surface. It is easy to suggest these radical(s) to react with molecular oxygen forming superoxide. Therefore, we assume that the second place which binds thyroid hormones with high affinity and is responsible for suppression of superoxide formation is localized on one of the outer small subunits of the mitochondrial enzyme. It is noteworthy that bacterial $\mathrm{CcO}$ lacking additional subunits does not form $\mathrm{O}^{2^{-}}$ under the same conditions (red curve 2 in Figure 7a). The mechanism of inhibition could consist, for example, in shielding a free radical group on the surface of the enzyme by a hormone molecule thus preventing the contact with $\mathrm{O}_{2}$. Quite probably, this scenario should not be regarded as associated with the pseudocatalase cycle exclusively since the chance of an electron vacancy migration to the protein surface exists even in $\mathrm{CcO}$ operating along a complete catalytic cycle.

It is of interest that the first data on the direct interaction of hormones with mitochondrial $\mathrm{CcO}$ were obtained by the groups of Goglia and Kadenbach in the mid-90s and were related just to the thyroid hormone T2 $[59,60]$. According to the authors, T2 binds with extremely high (micromolarsubmicromolar) affinity to the Va subunit of mitochondrial $\mathrm{CcO}$. This caused small changes in the absorption spectrum of the enzyme and its activation by about one and a half times as a result of the release from allosteric inhibition exerted by ATP molecules interacting with the matrix domain of the subunit IV. We were unable to reproduce the indicated effects of T2 which is most likely due to differences in the methods of enzyme isolation used in [59] and in our study. Nevertheless, we assume that in the case of inhibition of superoxide formation by thyroid hormones the same site on the Va subunit is concerned. As a result of interaction with it we observed the inhibition of one of the partial activities of the enzyme rather than modulation of its main activity described by the Goglia and Kadenbach groups, and the inhibiting agent in our case was not only T2, but T3 and T4 as well.

Although the question of the physiological role of the second binding site for thyroid hormones in mitochondrial $\mathrm{CCO}$ remains open, the high affinity for ligands hints that such a role exists. It could be just protective since superoxide and especially its derivatives damage intracellular structures chemically, with mitochondrion to be the most sensitive target (see for example [61]). Furthermore, $\mathrm{O}_{2}{ }^{--}$is known as a link of intracellular signaling pathways $[62,63]$ and the ability to prevent its formation makes thyroid hormones potential participants in the redox regulation system. 
Author Contributions: Conceptualization, T.V.V. and N.V.A.; methodology, T.V.V. and N.V.A.; software, T.V.V., N.V.A. and I.P.O.; validation, T.V.V., N.V.A. and I.P.O.; formal analysis, T.V.V., N.V.A. and I.P.O.; investigation, T.V.V. and I.P.O.; resources, T.V.V. and N.V.A.; data curation, T.V.V., N.V.A. and I.P.O.; writing-original draft preparation, T.V.V. and N.V.A.; writing-review and editing, N.V.A. and T.V.V.; visualization, T.V.V., N.V.A. and I.P.O.; supervision, T.V.V. and N.V.A.; project administration, T.V.V. and N.V.A.; funding acquisition, I.P.O. All authors have read and agreed to the published version of the manuscript.

Funding: This work was supported by the Russian Science Foundation (project 22-2400045), https://rscf.ru/en/project/22-24-00045/ (to I.P.O.).

Conflicts of Interest: The authors declare no conflict of interest. The funders had no role in the design of the study; in the collection, analyses, or interpretation of data; in the writing of the manuscript, or in the decision to publish the results.

\section{References}

1. Rich, P.R. Mitochondrial cytochrome $c$ oxidase: catalysis, coupling and controversies. Biochem. Soc. Trans. 2017, 45, 813-829. doi: 10.1042/BST20160139.

2. Wikström, M.; Sharma, V. Proton pumping by cytochrome $c$ oxidase - a 40 year anniversary. Biochim. Biophys. Acta (Bioenergetics) 2018, 1859, 692-698. doi: 10.1016/j.bbabio.2018.03.009.

3. Kadenbach, B; Hüttemann, M. The subunit composition and function of mammalian cytochrome c oxidase. Mitochondrion 2015, 24, 64-76. doi: 10.1016/j.mito.2015.07.002.

4. Pierron, D; Wildman, D.E; Hüttemann, M; Markondapatnaikuni, G.C.; Aras, S.; Grossman, L.I. Cytochrome c oxidase: evolution of control via nuclear subunit addition. Biochim. Biophys. Acta 2012, 1817, 590-597. doi: 10.1016/j.bbabio.2011.07.007.

5. Konstantinov, A. Cytochrome $c$ oxidase as a proton-pumping peroxidase: reaction cycle and electrogenic mechanism. J. Bioenerg. Biomembr. 1998, 30, 121-130. doi: 10.1023/a:1020571930850.

6. Konstantinov, A. A. Cytochrome $c$ oxidase: Intermediates of the catalytic cycle and their energy-coupled interconversion. FEBS lett. 2012, 586, 630-639. doi: 10.1016/j.febslet.2011.08.037.

7. Belevich, I; Verkhovsky, M.I. Molecular mechanism of proton translocation by cytochrome c oxidase. Antioxid. Redox Signal. 2008, 10, 1-29. doi: 10.1089/ars.2007.1705.

8. Siletsky, S.; Konstantinov, A.A. Cytochrome $c$ oxidase: charge translocation coupled to single-electron partial steps of the catalytic cycle. Biochim. Biophys. Acta 2012, 1817, 476-488. doi: 10.1016/j.bbabio.2011.08.003.

9. Qin, L.; Mills, D.A.; Buhrow, L.; Hiser, C.; Ferguson-Miller, S. A Conserved steroid binding site in cytochrome $c$ oxidase. Biochemistry 2008, 47, 9931-9933. doi: 10.1021/bi8013483.

10. Ferguson-Miller, S.; Hiser, C.; Liu, J. Gating and regulation of the cytochrome $c$ oxidase proton pump. Biochim. Biophys. Acta 2012, 1817, 489-494. doi: 10.1016/j.bbabio.2011.11.018.

11. Hiser, C.; Buhrow, L.; Liu, J.; Kuhn, L.; Ferguson-Miller, S. A conserved amphipathic ligand binding region influences K-path-dependent activity of cytochrome $c$ oxidase. Biochemistry 2013, 52, 1385-1396. doi: 10.1021/bi3014505.

12. Buhrow, L.; Hiser, C.; van Voorst, J.R.; Ferguson-Miller, S.; Kuhn, L.A. Computational prediction and in vitro analysis of potential physiological ligands of the bile acid binding site in cytochrome $c$ oxidase. Biochemistry 2013, 52, 6995-7006. doi: 10.1021/bi400674h.

13. Hiser, C.; Liu, J.; Ferguson-Miller, S. The K-path entrance in cytochrome c oxidase is defined by mutation of E101 and controlled by an adjacent ligand binding domain. Biochim. Biophys. Acta 2018, 1859, 725-733. doi: 10.1016/j.bbabio.2018.03.017.

14. Oleynikov, I.P.; Azarkina N.V.; Vygodina T.V.; Konstantinov A.A. Interaction of cytochrome $c$ oxidase with steroid hormones. Cells 2020, 9, 2211. doi: 10.3390/cells9102211.

15. Oleynikov, I.P.; Azarkina N.V.; Vygodina T.V.; Konstantinov A.A. Mechanism of inhibition of cytochrome $c$ oxidase by Triton X-100. Biochemistry (Moscow) 2021, 86, 44-58. doi: 10.1134/S0006297921010053.

16. Davis, P.J.; Tillmann, H.C.; Davis, F.B.; Wehling, M. Comparison of the mechanisms of nongenomic actions of thyroid hormone and steroid hormones. J. Endocrinol. Invest. 2002, 25, 377-388. doi: 10.1007/BF03344022.

17. Psarra, A.M.; Solakidi, S.; Sekeris, C.E. The mitochondrion as a primary site of action of steroid and thyroid hormones: presence and action of steroid and thyroid hormone receptors in mitochondria of animal cells. Mol. Cell. Endocrinol. 2006, 26, 21-33. doi: 10.1016/j.mce.2005.11.025.

18. Vaitkus, J.A; Farrar, J.S.; Celi, F.S. Thyroid Hormone Mediated Modulation of Energy Expenditure. Int. J. Mol. Sci. 2015, 16, 16158-16175. doi: 10.3390/ijms160716158.

19. Giammanco, M.; Di Liegro, C.M.; Schiera, G.; Di Liegro, I. Genomic and Non-Genomic Mechanisms of Action of Thyroid Hormones and Their Catabolite 3,5-Diiodo-L-Thyronine in Mammals. Int. J. Mol. Sci. 2020, $21,4140$. doi: 10.3390/ijms21114140. 
20. Bergmeyer, H.U.; Gawehn, K.; Grassl, M. In Methoden der Enzymatischen Analyze; Bergmeyer, H.U., Ed.; Verlag Chemie: Weinheim, Germany, 1970; p. 440.

21. Fowler, L.R.; Richardson, S.H.; Hatefi, Y. A rapid method for the preparation of highly purified cytochrome oxidase. Biochim. Biophys. Acta 1962, 64, 170-173. doi: 10.1016/0006-3002(62)90770-9.

22. Vygodina, T.V.; Kirichenko, A.; Konstantinov, A.A. Cation binding site of cytochrome $c$ oxidase: Progress report. Biochim. Biophys. Acta 2014, 1837, 1188-1195. doi: 10.1016/j.bbabio.2014.02.025.

23. Finel, M.; Wikstrom, M. Studies on the role of the oligomeric state and subunit III of cytochrome oxidase in proton translocation. Biochim. Biophys. Acta 1986, 851, 99-108. doi: 10.1016/0005-2728(86)90253-7.

24. Johnson, D.; Lardy, H. Isolation of liver or kidney mitochondria. Methods in Enzymology 1967, 10, 94-96.

25. Beyer, R.E. Preparation properties and conditions for assay of phosphorylating electron transport particles (ETP) and its variations. Methods in Enzymology 1967, 10, 186-194.

26. Hilbers, F.; von der Hocht, I.; Ludwig, B.; Michel, H. True wild type and recombinant wild type cytochrome $c$ oxidase from Paracoccus denitrificans show a 20-fold difference in their catalase activity. Biochim. Biophys. Acta 2013, 1827, 319-327. doi: 10.1016/j.bbabio.2012.10.008.

27. Bielski, B.H.; Shiue, G.G.; Bajuk, S. Reduction of nitro blue tetrazolium by $\mathrm{CO}_{2}$ - and $\mathrm{O}_{2}$ - radicals. J. Phys. Chem. 1980, 84, 830-833. doi: 10.1021/j100445a006.

28. Vanneste, W. H. The stoichiometry and absorption spectra of components $a$ and $a-3$ in cytochrome $c$ oxidase. Biochemistry 1966, 5, 838-848. doi: 10.1021/bi00867a005.

29. Reichardt, J.K.; Gibson, Q.H. Spectra of Intermediates in Oxidation and Reduction of Cytochrome $c$ Oxidase. J. Biol. Chem. 1982, 257, 9268-9270.

30. Nicholls, P.; Wrigglesworth, J.M. Routes of cytochrome a3 reduction. The neoclassical model revisited. Ann. NY Acad. Sci. 1988, 550, 59-67. doi: 10.1111/j.1749-6632.1988.tb35323.x

31. Vygodina, T.V.; Dyuba, A.V.; Konstantinov, A.A. Effect of calcium ions on electron transfer between hemes $a$ and $a_{3}$ in cytochrome $c$ oxidase. Biochemistry (Moscow) 2012, 77, 901-909. doi: 10.1134/S0006297912080111.

32. Konstantinov, A.A.; Vygodina, T.; Capitanio, N.; Papa, S. Ferrocyanide-peroxidase activity of cytochrome $c$ oxidase. Biochim. Biophys. Acta 1998, 1363, 11-23. doi: 10.1016/s0005-2728(97)00087-x

33. Yoshikawa, S.; Shimada, A. Reaction Mechanism of Cytochrome $c$ Oxidase. Chem. Rev. 2015, 115, 1936-1989. doi: 10.1021/cr500266a.

34. Bolshakov, I.A.; Vygodina, T.V.; Gennis, R.; Karyakin, A.A.; Konstantinov, A.A. Catalase activity of cytochrome c oxidase assayed with hydrogen peroxide-sensitive electrode microsensor. Biochemistry (Moscow) 2010, 75, 1352-1360. doi: 10.1134/s0006297910110064.

35. Babcock, G.T.; Wikström, M. Oxygen activation and the conservation of energy in cell respiration. Nature 1992, 356, 301-309. doi: 10.1038/356301a0.

36. Wikström, M.; Morgan, J.E. The dioxygen cycle. Spectral, kinetic, and thermodynamic characteristics of ferryl and peroxy intermediates observed by reversal of the cytochrome oxidase reaction. J. Biol. Chem. 1992, 267, 10266-10273.

37. Vygodina, T.V.; Konstantinov, A.A. Peroxidase activity of mitochondrial cytochrome $c$ oxidase. Biochemistry (Moscow) 2007, 72, 1056-1064. doi: 10.1134/s0006297907100045.

38. Wrigglesworth, J.M. Formation and reduction of a 'peroxy' intermediate of cytochrome $c$ oxidase by hydrogen peroxide. Biochem. J. 1984, 217, 715-719. doi: 10.1042/bj2170715.

39. Vygodina, T.; Konstantinov, A.A. Evidence for two $\mathrm{H}_{2} \mathrm{O}_{2}$-binding sites in ferric cytochrome $c$ oxidase. Indication to the O-cycle? FEBS lett. 1987, 219, 387-392. doi: 10.1016/0014-5793(87)80258-2.

40. Vygodina, T.V.; Konstantinov, A.A. $\mathrm{H}_{2} \mathrm{O}_{2}$-induced conversion of cytochrome $c$ oxidase peroxy complex to oxoferryl state. Ann. NY Acad. Sci. 1988, 550, 124-138. doi: 10.1111/j.1749-6632.1988.tb35329.x.

41. Konstantinov, A.A.; Capitanio, N.; Vygodina, T.V.; Papa, S. pH changes associated with cytochrome c oxidase reaction with $\mathrm{H} 2 \mathrm{O} 2$. Protonation state of the peroxy and oxoferryl intermediates. FEBS lett. 1992, 312, 71-74. doi: 10.1016/0014-5793(92)81412-f.

42. Ksenzenko, M.Yu.; Vygodina, T.V.; Berka, V.; Ruuge, E.K.; Konstantinov, A.A. Cytochrome oxidase-catalyzed superoxide generation from hydrogen peroxide. FEBS lett. 1992, 297, 63-66. doi: 10.1016/0014-5793(92)80328-e.

43. Vygodina, T.V.; Pecoraro, C.; Mitchell, D.; Gennis, R.; Konstantinov, A.A. Mechanism of inhibition of electron transfer by amino acid replacement K362M in a proton channel of Rhodobacter sphaeroides cytochrome $c$ oxidase. Biochemistry 1998, 37, 3053-3061. doi: 10.1021/bi971876u.

44. Tomson, F.L.; Morgan, J.E.; Gu, G.; Barquera, B.; Vygodina, T.V.; Gennis, R.B. Substitutions for glutamate 101 in subunit II of cytochrome $c$ oxidase from Rhodobacter sphaeroides result in blocking the proton-conducting Kchannel. Biochemistry 2003, 42, 1711-1717. doi: 10.1021/bi026750y.

45. Schiffer, L.; Barnard, L.; Baranowski, E.S.; Gilligan, L.C.; Taylor, A.E.; Arlt, W.; Shackleton, C.H.L.; Storbeck, K.H. Human steroid biosynthesis, metabolism and excretion are differentially reflected by serum and urine steroid metabolomes: A comprehensive review. J. Steroid Biochem. Mol. Biol. 2019, 194, 105439. doi: 10.1016/j.jsbmb.2019.105439. 
46. Carmina, E.; Stanczyk, F.Z.; Lobo, R.A. Evaluation of Hormonal Status. In Physiology, Pathology and Clinical Management Physiology, Pathology and Clinical Management, Elsevier, 2019, pp. 887-915.

47. Yao, Q.; Zhou, G.; Xu, M.; Dai, J.; Qian, Z.; Cai, Z.; Zhang, L.; Tan, Y.; Hu, R. Blood metal levels and serum testosterone concentrations in male and female children and adolescents: NHANES 2011-2012. PLoS One 2019, 14, e0224892. doi: 10.1371/journal.pone.0224892.

48. Shoshtari, S.Z.; Wen, J.; Alany, R.J. Octanol Water Partition Coefficient Determination for Model Steroids Using an HPLC Method. Lett. in Drug Design and Discovery 2008, 5, 394-400. doi:10.2174/157018008785777333.

49. D'Ascenzo, S.; Millimaggi, D.; Di Massimo, C.; Saccani-Jotti, G.; Botre, F.; Carta, G.; Tozzi-Ciancarelli, M.G.; Pavan, A.; Doloa, V. Detrimental effects of anabolic steroids on human endothelial cells. Toxicology Lett. 2007, 169, 129-136. doi: 10.1016/j.toxlet.2006.12.008.

50. Hong, H.; Nadesan, P.; Poon, R.; Alman, B.A. Testosterone regulates cell proliferation in aggressive fibromatosis (desmoid tumour). Br. J. Cancer. 2011, 104, 1452-1458. doi: 10.1038/bjc.2011.107.

51. Basile, J.R.; Binmadi, N.O.; Zhou, H.; Yang, Y.H.; Paoli, A.; Proia, P. Supraphysiological doses of performance enhancing anabolic-androgenic steroids exert direct toxic effects on neuron-like cells. Front. Cell Neurosci. 2013, 7, 69. doi: $10.3389 /$ fncel.2013.00069.

52. Domińska, K.; Kowalski, A. Ochędalski, T.; Rębas, E. Effects of testosterone and 17ß-estradiol on angiotensin-induced changes in tyrosine kinase activity in the androgen-independent human prostate cancer cell line, DU145. Int. J. Mol. Med. 2017, 40, 1573-1581. doi: 10.3892/ijmm.2017.3149.

53. Zelleroth, S.; Nylander, E.; Nyberg, F.; Grönbladh, A.; Hallberg, M. Toxic Impact of Anabolic Androgenic Steroids in Primary Rat Cortical Cell Cultures. Neuroscience 2019, 397, 172-183. doi: 10.1016/j.neuroscience.2018.11.035.

54. Michel, H. Cytochrome $c$ oxidase: catalytic cycle and mechanisms of proton pumping--a discussion. Biochemistry 1999, 38, 15129-15140. doi: 10.1021/bi9910934.

55. Jünemann, S.; Heathcote, P.; Rich, P.R. The reactions of hydrogen peroxide with bovine cytochrome $c$ oxidase. Biochim. Biophys. Acta 2000, 1456, 56-66. doi: 10.1016/s0005-2728(99)00105-x.

56. Pecoraro, C.; Gennis, R.B.; Vygodina, T.V.; Konstantinov, A.A. Role of the K-channel in the pH-dependence of the reaction of cytochrome $c$ oxidase with hydrogen peroxide. Biochemistry 2001, 40, 9695-9708. doi: 10.1021/bi010115v.

57. Qin, L.; Hiser, C.; Mulichak, A.; Garavito, R.M.; Ferguson-Miller, S. Identification of conserved lipid/detergentbinding sites in a high-resolution structure of the membrane protein cytochrome $c$ oxidase, Proc. Natl. Acad. Sci. U.S.A. 2006, 103, 16117-16122. doi: 10.1073/pnas.0606149103.

58. Jancura, D.; Stanicova, J.; Palmer, G.; Fabian, M. How hydrogen peroxide is metabolized by oxidized cytochrome c oxidase. Biochemistry 2014, 53, 3564-3575. doi: 10.1021/bi401078b.

59. Goglia, F.; Lanni, A.; Barth, J.; Kadenbach, B. Interaction of diiodothyronines with isolated cytochrome c oxidase. FEBS lett. 1994, 346, 295-298. doi: 10.1016/0014-5793(94)00476-5.

60. Arnold, S.; Goglia, F.; Kadenbach, B. 3,5-Diiodothyronine binds to subunit Va of cytochrome-c oxidase and abolishes the allosteric inhibition of respiration by ATP. Eur. J. Biochem. 1998, 252, 325-330. doi: 10.1046/j.14321327.1998.2520325.x.

61. Bhatti, J.S.; Bhatti, G.K.; Reddy, P.H. Mitochondrial dysfunction and oxidative stress in metabolic disorders - A step towards mitochondria based therapeutic strategies. Biochim. Biophys. Acta 2017, 1863, 1066-1077. doi: org/10.1016/j.bbadis.2016.11.010

62. Sena, L.A.; Chandel, N.S. Physiological roles of mitochondrial reactive oxygen species. Mol. Cell 2012, 48, 158167. doi: org/10.1016/j.molcel.2012.09.025.

63. Brand, M.D. Mitochondrial generation of superoxide and hydrogen peroxide as the source of mitochondrial redox signaling. Free Rad. Biol.Med. 2016, 100, 14-31. doi: org/10.1016/j.freeradbiomed.2016.04.001. 